DIW BERLIN

Discussion

Papers

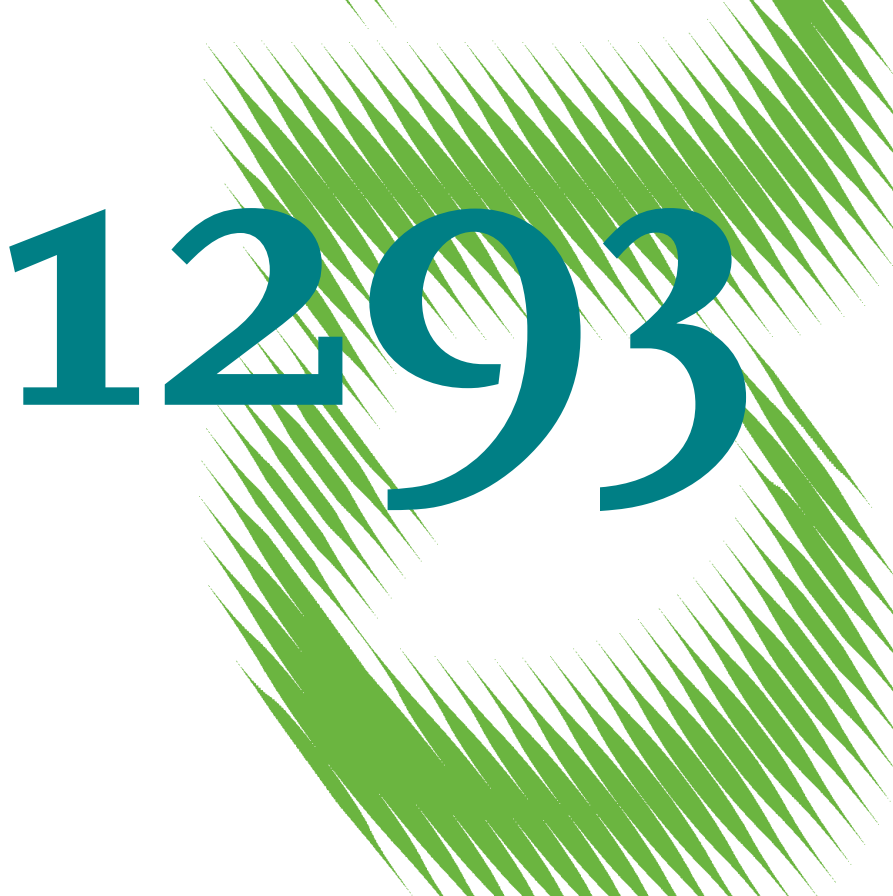

Estimating Crowding Costs in Public Transport 
Opinions expressed in this paper are those of the author(s) and do not necessarily reflect views of the institute.

IMPRESSUM

(C) DIW Berlin, 2013

DIW Berlin

German Institute for Economic Research

Mohrenstr. 58

10117 Berlin

Tel. $+49(30) 89789-0$

Fax +49 (30) $89789-200$

http://www.diw.de

ISSN print edition $1433-0210$

ISSN electronic edition 1619-4535

Papers can be downloaded free of charge from the DIW Berlin website:

http://www.diw.de/discussionpapers

Discussion Papers of DIW Berlin are indexed in RePEc and SSRN:

http://ideas.repec.org/s/diw/diwwpp.html

http://www.ssrn.com/link/DIW-Berlin-German-Inst-Econ-Res.html 


\title{
Estimating Crowding Costs in Public Transport
}

\author{
Luke Haywood*Martin Koning ${ }^{\dagger}$
}

April 2013

\begin{abstract}
Preferences for transport activities are often considered only in terms of time and money. Whilst congestion in automobile traffic increases costs by raising trip durations, the same is less obvious in public transport (PT), especially rail-based. This has lead many economic analyses to conclude that there exists a free lunch by reducing the attractiveness of automobile transport at no (or little) cost for PT users.

This article argues that congestion in PT - crowding - is also costly. Using survey data from the Paris metro we estimate the degree to which users value comfort in terms of less crowding. Using a contingent valuation method (CVM) we describe marginal willingness to pay over different parts of the distribution of in-vehicle crowding and consider moderating factors. We conclude that the total welfare cost for a trip rises from $€ 2.42$ for a seated passenger to $€ 3.69$ under the most congested conditions.

We apply our results to the cost-benefit analysis of a recent investment in PT in Paris and consider broader implications for transport policy. In particular, we highlight that PT congestion is a first-order urban externality.
\end{abstract}

Keywords: Evaluation of non-market goods, travel comfort, crowding costs, contingent valuation method, Paris subway

JEL Codes: D6, H8, R4, L9

*DIW Berlin, Public Economics Department, Mohrenstr. 58, 10117 Berlin, Germany, $+49(0) 3089789$ 320, LHaywood@diw.de.

${ }^{\dagger}$ Université Paris Est, IFSTTAR-SPLOTT, Bvd Newton 14-20, Cité Descartes, 77447 Marne-la-Vallée, France, +33(0)1 8166 8780, martin.koning@ifsttar.fr. 


\section{Introduction}

From an economic perspective, good urban transport policy makes efficient use of the scarce ressources time and space, subject to public budget constraints. It has come to be accepted that past policies have led to inefficiently high automobile usage in many countries (Newman and Kenworthy (1989), Parry et al. (2007)). Transport policies have thus typically focused on modal shift strategies: increasing the patronage of PT systems, especially with the use of congestion or environmental tolls for cars (Lindsey (2006), Tsekeris and Voss (2009)) or subsidies for PT (Parry and Small $(2009)^{1}$ ). Nevertheless, not always were such policies accompanied by increased PT supply. Where supply elasticity is low - as is the case for most rail-based PT systems - density of passangers in PT systems will consequently increase.

The traditional view assumes that transport users' utility depends on time and money only (Small and Verhoef (2007)). Under this perspective, as long as the saturation point of PT is not reached (Kraus and Yoshida (2002)), increasing PT usage should almost always lead to a societal gain. In fact, with more individuals sharing the fixed costs of PT provision, there will be economies of scale, such as a higher frequency of vehicles in the PT network (Mohring (1972), Proost and Dender (2008)). Reduced road congestion decreases costs of automobile transits and environmental externalities (Parry et al. (2007), Malibach et al. (2008)). However, this ignores comfort costs of PT congestion occurring well before the network reaches a bottleneck. Considering that the individuals care about the amount of space in vehicles, i.e. the inverse of passanger density, crowded travel conditions may decrease their utilities even if travel time is kept constant. Therefore, there is no free lunch by decreasing the attractiveness of automobile transport without improving the supply of PT.

This article examines the utility costs of PT congestion using contingent valuation methodology (CVM, see Haab and McConnel (2003) or Mitchell and Carson (1989)) on a survey collected late 2010 in the Paris subway. We use declared preferences on hypothetical states of nature in order to estimate the marginal willingness to pay for less crowded travelling conditions. PT crowding appears to be a first-order urban externality.

\footnotetext{
${ }^{1}$ Alternative non-motorised modes of transport such as bicycles, walking etc. have also been encouraged but have rarely been the main focus of the discussion.
} 
While numerous papers have been interested in estimating road congestion costs (Small and Verhoef (2007)), academic work on crowding of PT systems is rare. Studies on urban transport policies generally attribute an insignificant value to the crowding effect. For example, Parry and Small (2009) are interested in the optimal level of PT subsidies. Whereas they consider crowding costs as a dimension of the two modes problem in their theoretical analysis, they neglect them when calibrating their model empirically. This asymetry between road and PT congestion contradicts the theoretical formulation of PT usage cost initiated by Kraus (1991), and complexified thereafter (Jara-Diaz and Gschwender (2003), de Palma et al. (2011), Feifei and Haicheng (2011)). In practice, empirical evidence on PT crowding has mainly been assessed in technical (and unpublished) studies conducted by British and Australian consulting firms (see Li and Hensher (2011) or Wardman and Whelan (2011)).

The Paris area is a good case in point to investigate PT crowding costs. Over the last ten years, the city centre has seen a reallocation of road space from cars to cleaner transport modes (buses, streetcars, bikes). This popular policy of quantity regulation (Prud'homme and Kopp (2008)) - contrasting with systems of price regulation put forward in London or Stockholm - has reduced the average speed of cars in Paris by $10 \%$ between 2000 and 2007 (Observatoire de la mobilité de la ville de Paris (2007)). Following the rise of travel costs for cars, individual motorised traffic with Paris as destination or origin has diminished by $24 \%$ (in passanger-km, pkm, see Kopp (2011)). Whilst usage of motorbikes and bicycles has increased, the majority of the modal switch seems to have occured towards the PT network.

Table 1: Evolution of the Paris subway's usage

\begin{tabular}{|l|c|c|c|c|}
\hline & $\begin{array}{c}\text { Demand } \\
(\mathrm{M} \text { pass-km) }\end{array}$ & $\begin{array}{c}\text { Supply } \\
(\mathrm{M} \text { train-km) }\end{array}$ & $\begin{array}{c}\text { Density } \\
\left(\mathrm{pass} / \mathrm{m}^{2}\right)\end{array}$ & $\begin{array}{c}\text { Regularity } \\
(\%)\end{array}$ \\
\hline Paris subway & 6,011 & 42 & 1.0 & 98 \\
2000 & 7,353 & 48 & 1.1 & 98 \\
2009 & & & & \\
\hline
\end{tabular}

Sources: Syndicat des Transports de la Région Ile-de-France (2009) and Observatoire de la mobilité de la ville de Paris (2000). For the density indicator we assume that a train has 557 places, $139 \mathrm{~m}^{2}$. The regularity indicator is defined as the share of travellers who wait less than 3 minutes during peak periods. 
As illustrated in table (1), PT patronage in the Paris subway increased by $22 \%$ between 2000 and 2009 such that now $60 \%$ of all trips in Paris made use of the rail-based PT (on at least part of the journey). However, subway supply could not keep up with the increased demand. Note that there is no indication that the Paris subway is at a bottleneck ${ }^{2}$, where demand negatively affects regularity. Rather, the main effect appears to have been a reduction in comfort: in-vehicle passenger density grew by $10 \%$ between 2000 and 2009, whilst the regularity indicator remained constant. Thus we restrict our analysis here to the comfort costs of PT crowding. Combined with growing road congestion (Prud'homme and Kopp (2008)), the deterioration of PT travel conditions has been quoted as an important factor affecting job quality in the greater Paris region (Technologia (2010), ORSTIF (2010)). Commuters' complaints also figured prominently in municipal and regional elections in 2008 and 2010.

The rest of the paper is organized as follows. Section (2) presents the theoretical framework used to value PT crowding costs - based on CVM and reviews previous findings in this area. Section (3) focuses on the survey collected on the platforms of lines 1 and 4 of the Paris subway. Section (4) presents the empirical strategy and results, showing how increasing density causes crowding costs to rise. Using the estimated values of PT crowding costs, section (5) highlights policy implications. We show how taking into account PT crowding can influence cost-benefift anaylses in an economic appraisal of the introduction of driverless trains in the Paris metro. Section (6) concludes.

\section{Valuing Crowding Costs using Contingent Valu- ation}

In order to assess the welfare costs of PT crowding, we write the utility of PT user $i$ at congestion level $j\left(U_{i, j}\right)$ as a function of in-vehicle travel time $t_{i}$, monetary expenditures $p_{i}$ and an indicator function for the level of comfort $c_{j} \in\{0, \ldots, J\}$ where $J$ is the most comfortable (least crowded) condition. The two first arguments, money and time, are standard. They determine the generalized cost of travels once time ressources are valued at their opportunity cost (a function of individuals' income). We propose to

\footnotetext{
${ }^{2}$ Note that this refers only to the subway system in the centre of Paris (métro), not the regional system (RER).
} 
integrate comfort as a factor moderating the influence of trip duration. This is in line with the idea of comfort as a factor moderating flow utility, not a fixed utility cost. Individual characteristics $X_{i}$ may also influence utility:

$$
U_{i, j}=\alpha+\theta p_{i}+\sum_{j=0}^{J} c_{j} \beta_{j} t_{i}+\delta X_{i}+\varepsilon_{i}
$$

In the simplest case, in-vehicle crowding is just characterized by two states of nature $(j=0$ for peak periods in which transport users must stand and $j=1$ for off-peak periods in which PT users are seated), the welfare difference due to travel comfort is linked to the marginal disutilities of invehicle time $\left(\beta_{j}<0\right)$. We find:

$$
\begin{aligned}
U_{i, 1}-U_{i, 0} & >0 \\
\left(\beta_{1}-\beta_{0}\right) t_{i} & >0 \\
\Rightarrow 0 & >\beta_{1}>\beta_{0}
\end{aligned}
$$

This formulation is consistent with a wide range of reasons for preferring less congested PT. Data on satisfaction in transport is lower when individuals lack space in vehicles (Cantwell et al. (2009)), and low density is quoted as one of the main qualitative attributes desired by PT users (Litman (2008), dell'Olio et al. (2011)). Crowding on PT networks reduces the probability that passangers find a seat in carriages and prevents individuals from using time for other activities (polychronic use of time). Congestion in PT may also induce security fears, increase noise levels and reduce hygiene ( $\mathrm{Li}$ (2003), CRCFRI (2012)). All these effects increase personal stress, with effects found on mortality and productivity losses at the workplace (Wener et al. (2005), Evans and Wener (2007), Cox et al. (2006)). These costs are not fixed per trip but rather they continue throughout the trip - thus they modify the cost of time: each minute spent in $j=0$ is more painful for travellers than the same minute consumed in $j=1$.

\subsection{Finding the equivalent variation}

Comfortable travel conditions constitute a non-market good which is not directly priced. To recover the welfare cost of PT crowding, two strategies can be taken: the first is based on observed behaviors (revealed preferences ${ }^{3}$ )

\footnotetext{
${ }^{3}$ Among them, the hedonic price and transport costs methods, see Haab and McConnel (2003).
} 
whilst the second uses stated preferences in response to hypothetical scenarios. CVM belongs to the latter approach (Haab and McConnel (2003), Mitchell and Carson (1989)). The basic idea is to find the equivalent variation in economic resources which makes individuals indifferent between states with different levels of the non-market good $\left(U_{i, 1}=U_{i, 0}\right)$. CVM has been used extensively by environmental economists, but also in the valuation of transport externalities and to assess the subjective cost of travel time (Ward$\operatorname{man}(2001))$.

For reasons outlined below (see section (3.1)), our survey proposes scenarios in terms of longer commuting time (rather than financial cost) in exchange for less congested PT. Starting from the indifference condition, the proposed trade-off between travel time and comfort then allows us to study two types of equivalent variation. First, willingness to pay $(W T P)$ is the additional travel time in the less congested state which would leave individuals indifferent with the more congested state:

$$
\begin{aligned}
U_{i, 1} & =U_{i, 0} \\
\beta_{0} t_{i} & =\beta_{1}\left(t_{i}+W T P\right) \\
W T P & =t_{i} \frac{\left(\beta_{0}-\beta_{1}\right)}{\beta_{1}}
\end{aligned}
$$

The equivalent variation can also be expressed as a change in the marginal disutility of travel time $\beta_{j}$, a "time multiplier" ( $T m$, see Wardman and Whelan (2011)):

$$
\begin{aligned}
U_{i, 1} & =U_{i, 0} \\
\beta_{0} t_{i} & =\beta_{1} t_{i} T m \\
T m & =\frac{\beta_{0}}{\beta_{1}}>1
\end{aligned}
$$

The $T m$ is the marginal rate of substitution of travel time between peak and off-peak comfort levels. In fact, it corresponds to the ratio of the marginal disutilities between congested and non-congested states. To express crowding costs in monetary terms, we apply a monetary measure of the time opportunity cost to our estimate of $W T P$, i.e. PT congestion costs will be expressed in $€ /$ trip, or for the $T m$ in $€ /$ hour. Finally, note that the two types of valuation are linked by the following relationship:

$$
W T P=t_{i}(T m-1)
$$




\subsection{Crowding costs in the literature}

Other studies have used CVM to appraise PT crowding costs, however work has mainly focused on the UK and Australia and not been published. Surveys by Li and Hensher (2011) and Wardman and Whelan (2011) have made findings more accessible for economists. Valuations in terms of $\mathrm{Tm}$ are preferred since they are more easily comparable accross services and places. According to the meta-analysis of Wardman and Whelan (2011) conducted on 17 British studies, the average Tm ranges from 1.60 to 2.00 for load factors comprised between 100\% and 200\% . Li and Hensher (2011) and Douglas and Karpouzis (2006) report time multipliers of 1.34-2.00 for the Australian PT network, around 0.43-2.43 AUS dollars/trip equivalent to a majoration of time opportunity cost by 0.97-11.27 AUS dollars/hour. PT crowding costs are also reported to be influenced by in-vehicle travel time and trip motives (with higher valuations for non-commuting).

The Boiteux report (Ministère de l'Equipement (2005), Commissariat Général du Plan (2001)) provides the reference values used for cost-benefit analysis of transport policies in France. Without specific scientific guidance it advises to increase the opportunity cost of travel duration by a factor of 1.5 when travellers cannot be seated during their trip. Debrincat et al. (2006) consider crowding as a component of the welfare impact of trains' reliability in the Greater Paris region. They combine different wating times, levels of information for users and comfort situations (seat, stand, stand in crowded conditions) and find that the discomfort generated by standing during the trip corresponds to a WTP of 5-20 minutes, depending on the trains' load factor and travel duration. This result is similar to a $T m$ ranging from 1.301.90 .

Using an earlier survey, Haywood and Koning (2012) consider crowding costs in the line 1 of the Parisian subway during morning peaks. They find a $W T P$ estimates in the range of 5.7-8.1 minutes. This implies crowding costs of $€ 1.01-1.46 /$ trip, i.e. around twice the average fare currently paid by the Parisian PT network's users, or a time multiplier ranging from 1.3-1.4. Using these data, Prud'homme et al. (2012) consider various policy implications of PT congestion. Despite promising findings, the survey design suffered some weaknesses, especially with respect to the hypothetical changes proposed to

\footnotetext{
${ }^{4}$ The load factor is defined as the ratio of transport users over seating in public transport. As in-vehicle transport design varies considerably, we prefer to focus on user density by space (not seats).
} 
PT users and the bidding design. The newly available survey used here incorporates several key innovations ${ }^{5}$.

\section{Survey Design and Data}

Our data were collected between November 2010 and January 2011 on lines 1 and 4 of the Paris subway. Interviews were carried out during extended morning and evening rush hours (50\% between $7.30-10.00$ and $50 \%$ between 17.00-19.30), directly on the platforms of 11 representative stations ${ }^{6}$.

Crossing Paris East-West, line 1 is the busiest service of the Paris network (with 750,000 users per day). It connects the PT users to most of the strategic centers (economic, tourism) of Paris. Crossing Paris North-South, line 4 faces a smaller patronage than line 1 (670,000 users per day). It is the second busiest line of the network. Taken jointly, the two lines give access to the most important residential, touristic and business amenities of Paris, but also include some of the poorest neighbourhoods of the city, generating a diverse initial sample of 800 PT users. Respondents answered the questions whilst waiting for their train to arrive in order to minimize selection bias stemming from selective non-response.

\subsection{Temporal congestion reduction scenarios}

To describe the level of passanger density in PT, we use showcards. First, users were asked to determine their expectation of passenger density during peaks (corresponding to $0,1,2,2.5,3,4$ or 6 passengers per square metre, see figure (1)) - this is the density that users expect to face in the train they

\footnotetext{
${ }^{5}$ First, Haywood and Koning (2012) only considered the (discrete) gap between peak and off-peak periods, the latter situation being improperly defined and highly subjective. Second, the first study used a non-random bidding process, which always started with a 5 minutes offer whilst adding a follow-up question only for individuals who accepted the initial trade-off. Third, individuals may be more prone to reject the trade-off between travel time and comfort in the morning because of the induced delays and the existence of scheduling costs (Arnott et al. (1990)). Finally, data on the in-vehicle travel duration relied only on self-reported trip duration.

${ }^{6}$ Line 1, morning peak: Gare de Lyon, Hôtel de Ville and Champs-Elysées; Line 4, morning peak: Denfert-Rochereau, Montparnasse and Odéon; Line 1, evening peak: Esplanade de la Défense, Argentine, Georges $V$; Line 4, evening peak: Les Halles, Odéon and Saint-Sulpice.
} 
are about to take.

\section{Le confort dans le métro parisien}

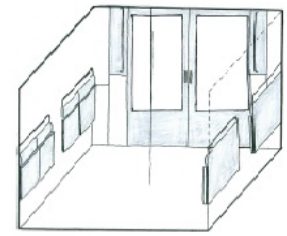

Carte 1

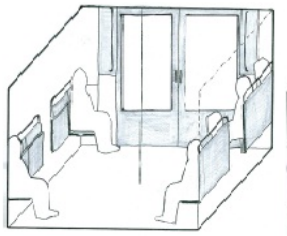

Carte 2

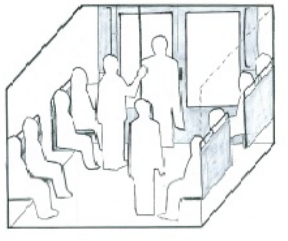

Carte 3

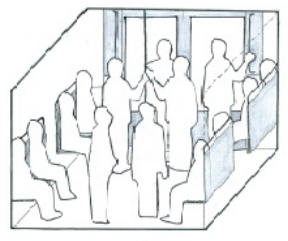

Carte 4

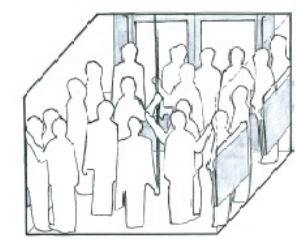

Carte 5

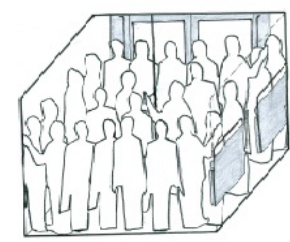

Carte 6

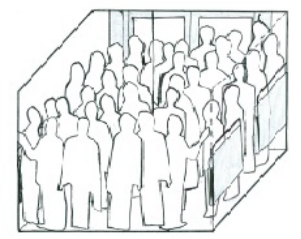

Carte7

Figure 1: Showcard used during the field survey

A hypothetical density reduction from this reference point was proposed (the density reduction was drawn from a uniform distribution). We then randomly proposed a first temporal bid $(3,6,9,12,15,18$ minutes, see appendix (7.1)). Whilst open questions or payment cards could provide more precise values, the binary format with discrete choices is said to better mimic individuals' everyday decisions (Haab and McConnel (2003), Mitchell and Carson (1989)). Moreover, the second bid was increased (decreased) by $25 \%$ for individuals who accepted (refused) the first bid, in line with the "doublebounded" model (see Hanemann et al. (1991) or Haab and McConnel (2003)).

The CVM elicits intentions rather than assessing behaviour. In the context of PT comfort valuation, there are at least two advantages of not proposing monetary bids but rather phrasing bids in temporal terms:

First, it reduces the risk that individuals freeride on others' contributions by under- or over-reporting (strategic bias). In our case this is particularly 
relevant as monetary costs are highly subsidised both publicly and by employers.

Second, it makes it easier for individuals to envisage the proposed scenario (reducing the so-called hypothetical bias): travellers confronted with overcrowded vehicles sometimes let a train pass before taking a space on the next one. Commuters may equally adjust their departure/arrival times in order to avoid congested trains, or adjust their routes accordingly.

Finally, we use information on objective trip conditions. The PT operator only provided us with information on average density for selected sections of lines 1 and 4 for 2008. In addition of being old compared to the field survey (2010), these data are for entire vehicles whilst we are mainly interested in the carriages' central area as described on the showcard. Therefore we manually counted passenger density in January and February 2011 in over 80 trains. We also measured travel times necessary to connect different pairs of stations on lines 1 and 4 . These statistics help us to reconstruct individuals' objective trip characteristics.

\subsection{Descriptive statistics}

The response rate of PT users for the survey was around $60 \%{ }^{7}$. Complete data were available for 668 individuals.

Table (2) shows that the average interviewee is aged 35 years, with equal numbers of women and men. $57 \%$ of the individuals live in the centre of Paris (62\% of line 4 users and $53 \%$ in line 1), $94 \%$ in the greater Paris area. Only $38 \%$ of our sample owns a car. Average monthly income is $€ 2,440$, with wealthier individuals in line $1(€ 2,798)$. Using this information, it was possible to calculate an individualised opportunity cost of time with a mean value of $€ 0.20$ per minute in $2010(€ 12 / \mathrm{h}$ ), close to the value implied by the Boiteux report (€10.70/h in 2010, see Commissariat Général du Plan (2001)).

Table (3) shows that most trips are between home and the workplace (70\% overall, higher in line $1-78 \%$ - and in the morning - 76\%). Most trips were taken daily (64\%) which should help individuals evaluate scenarios of

\footnotetext{
${ }^{7}$ Interviewers were instructed to report estimated values for age and gender of individuals refusing to take part in the survey. Older individuals tend to participate less often, with no obvious gender differentials.
} 
Table 2: Individual characteristics

\begin{tabular}{|l|c|c|c|c|c|}
\hline & Total & Line 1 & Line 4 & Morning & Evening \\
\hline Age (years) & & & & & \\
Male (\%) & 35 & 36 & 34 & 35 & 35 \\
Parisian (\%) & $50 \%$ & $49 \%$ & $51 \%$ & $50 \%$ & $50 \%$ \\
Francilian (\%) & $57 \%$ & $53 \%$ & $62 \%$ & $56 \%$ & $59 \%$ \\
Car's ownership (\%) & $94 \%$ & $94 \%$ & $95 \%$ & $92 \%$ & $96 \%$ \\
Income (euros/month) & $38 \%$ & $43 \%$ & $33 \%$ & $39 \%$ & $37 \%$ \\
Time opportunity cost (euro/min) & 2,440 & 2,798 & 2,097 & 2,589 & 2,286 \\
\hline
\end{tabular}

Source: Field survey on platforms.

Notes: In order to entice individuals to truthfully reveal their income in a public space, we used a card representing 8 income categories, each with a different colour. Following D4E (2005), we calculate the time opportunity cost $\left(w_{i}\right)$ from individual incomes $\left(y_{i}\right)$ by considering 135 worked hours per month: $w_{i}=(2 / 3) * y_{i} / 135$

Table 3: Descriptive statistics of trips

\begin{tabular}{|l|c|c|c|c|c|}
\hline & Total & Line 1 & Line 4 & Morning & Evening \\
\hline Home-Work (\%) & & & & & \\
Line daily usage (\%) & $70 \%$ & $78 \%$ & $62 \%$ & $76 \%$ & $64 \%$ \\
"Door-to-door" travel time (minutes) & 46 & $66 \%$ & $62 \%$ & $63 \%$ & $65 \%$ \\
Number of inter-stations & 6.8 & 7.2 & 64 & 51 & 41 \\
In-vehicle travel time (minutes) & 9.6 & 11.5 & 7.9 & 6.8 & 6.8 \\
Distance travelled (kilometers) & 3.8 & 5.1 & 2.6 & 3.7 & 9.9 \\
\hline
\end{tabular}

Sources: Field survey on platforms and RATP, i.e. the PT operator, website for distances' figures.

Note: The average inter-station distance strongly differs between lines 1 and $4(0.7 \mathrm{~km} / \mathrm{station}$ and $0.4 \mathrm{~km} / \mathrm{station})$. 
congestion. Reported door-to-door travel time was on average 46 minutes, in-vehicle trip duration (9.6 minutes, 11.5 in line 1 and 7.9 in line 4) only repesenting $21 \%$ of total travel duration. The in-vehicle time budget corresponds to $€ 1.90 /$ trip. This amounts to over three times the single fare paid by Parisian PT users. Because of higher time opportunity cost and travel time, the time component is larger for line $1(€ 2.65 /$ trip versus $€ 1.34$ on line 4).

Table 4: Expected density

\begin{tabular}{|l|c|c|c|c|c|c|c|}
\hline Expected density $\left(\mathbf{p a s s} / \mathbf{m}^{2}\right)$ & $\mathbf{0}$ & $\mathbf{1}$ & $\mathbf{2}$ & $\mathbf{2 . 5}$ & $\mathbf{3}$ & $\mathbf{4}$ & $\mathbf{6}$ \\
\hline Total & & & & & & & \\
\hline Line 1 & $0.0 \%$ & $2.3 \%$ & $16.6 \%$ & $27.8 \%$ & $23.9 \%$ & $20.5 \%$ & $8.8 \%$ \\
Line 4 & $0.0 \%$ & $1.2 \%$ & $8.5 \%$ & $20.4 \%$ & $25.8 \%$ & $28.9 \%$ & $15.2 \%$ \\
\hline Morning & $0.0 \%$ & $3.4 \%$ & $24.4 \%$ & $35.0 \%$ & $22.0 \%$ & $12.4 \%$ & $2.7 \%$ \\
Evening & $0.0 \%$ & $3.2 \%$ & $21.6 \%$ & $29.3 \%$ & $21.6 \%$ & $17.8 \%$ & $6.5 \%$ \\
& $0.0 \%$ & $1.5 \%$ & $11.5 \%$ & $26.3 \%$ & $26.3 \%$ & $23.3 \%$ & $11.2 \%$ \\
\hline
\end{tabular}

Source: Field survey on platforms.

Table (4) presents the distribution of the expected density in trains. Note that this information corresponds to the reference point for later scenarios of reduced congestion. Only $2 \%$ think they will find an empty seat (the threshold being 1 pass $/ \mathrm{m}^{2}$ on the showcard), with no single person expecting an empty train. At the other extreme, less than $10 \%$ of the sample expect to face the worst travel conditions $\left(6\right.$ pass $\left./ \mathrm{m}^{2}\right)$. This proportion is five times higher for line 1 (15\%) than for line 4 (3\%). As illustrated in table (5), average expected density is 3.1 pass $/ \mathrm{m}^{2}$, with important variations between lines 1 and 4 (3.5 pass $/ \mathrm{m}^{2}$ versus 2.7 pass $\left./ \mathrm{m}^{2}\right)$ and between mornings and evenings $\left(2.9 \mathrm{pass} / \mathrm{m}^{2}\right.$ versus $\left.3.3 \mathrm{pass} / \mathrm{m}^{2}\right)$. These figures are highly correlated with the objective passanger density faced, in average, by users during their trips: 2.3 pass $/ \mathrm{m}^{2}$ considering the count data; 1.7 pass $/ \mathrm{m}^{2}$ with the 2008 agregated data from the PT operator.

Exploratory estimates conducted with an ordered logit (see table (15) in appendix (7.3)) confirm that reference points are significantly influenced by objective levels of density (manual count data and official data). In line with this information, the expected density appears to be higher for line 1 users and for individuals interviewed during evening peaks. The only individual 
Table 5: Density indicators

\begin{tabular}{|l|c|c|c|c|c|}
\hline & Total & Line 1 & Line 4 & Morning & Evening \\
\hline Expected density $\left(\mathbf{p a s s} / \mathbf{m}^{2}\right.$ ) & 3.1 & 3.5 & 2.7 & 2.9 & 3.3 \\
\hline Count density (pass $/ \mathbf{m}^{2}$ ) & 2.3 & 2.9 & 1.5 & 2.4 & 2.3 \\
Ratp density (pass $/ \mathbf{m}^{2}$ ) & 1.7 & 2.2 & 1.3 & 1.6 & 1.9 \\
\hline
\end{tabular}

Sources: Count data (over 80 trains departures) and Ratp data (2008).

characteristics affecting perception of density are monthly income and doorto-door travel time ${ }^{8}$.

\subsection{Hypothetical scenarios}

Before presenting our empirical strategy, we provide some descriptive statistics on the hypothetical scenarios presented to travellers. We propose random (time) bids and random reductions in passanger density (appendix (7.1) shows the distributions). On average, passangers are offered a reduction in density of 1.8 pass $/ \mathrm{m}^{2}$, corresponding to $60 \%$ of baseline density. The average value of the first bid proposed to interviewees amounts to a lengthening of their trip by 8.7 minutes. Using the time opportunity cost, the temporal bid is equivalent to $€ 1.80$ per trip, close to the valuation of current in-vehicle travel time.

The acceptance rate for the first bid is $42 \%$ (49\% in line 1 and $34 \%$ in line $4 ; 45 \%$ in the evening and $38 \%$ in the morning rush hour). These results are consistent with the data on objective congestion, but also with the idea that scheduling costs may be higher in the morning, reducing the ability of workers to increase their trip duration at this margin. Because less than $50 \%$ of the sample accepted the first hypothetical scenario, the second bid is slightly lower than the first (8 minutes). We observe that the rate of positive answers is stable accross rounds (42\%). Appendix (7.2) considers an alternative decomposition of descriptive statistics by sequences of responses to bids.

\footnotetext{
${ }^{8}$ The in-vehicle travel time does not present any significant effect on the expected density. This result is useful for the empirical study of declared preferences since it means that $c_{j}$ and $t_{i}$ in equation (1) are orthogonal.
} 
Table 6: Descriptive statistics on hypothetical scenarios

\begin{tabular}{|l|c|c|c|c|c|}
\hline & Total & Line 1 & Line 4 & Morning & Evening \\
\hline Expected density (pass $/ \mathbf{m}^{\mathbf{2}}$ ) & 3.1 & 3.5 & 2.7 & 2.9 & 3.3 \\
Hypothetical density (pass $\mathbf{m}^{2}$ ) & 1.3 & 1.5 & 1.1 & 1.1 & 1.4 \\
\hline Bid 1 (minutes) & 8.7 & 8.5 & 8.9 & 8.8 & 8.6 \\
Answer 1 positive (\%) & $42 \%$ & $49 \%$ & $34 \%$ & $38 \%$ & $45 \%$ \\
\hline Bid 2 (minutes) & 8.0 & 8.1 & 7.9 & 7.9 & 8.2 \\
Answer 2 positive (\%) & $42 \%$ & $43 \%$ & $40 \%$ & $40 \%$ & $43 \%$ \\
\hline
\end{tabular}

Source: Field survey on platforms.

\section{Empirical Study of the Stated Preferences}

Our econometric strategy focuses on the parameters of the utility function, which allows us to compute the time multipliers ${ }^{9}$. Following the specification proposed in section (2), we now give individuals faced with travel time $t_{i}$ and current level of comfort $j$ the opportunity of improving their level of comfort in an hypothetical scenario $k=P$ at the cost of accepting longer travel time. The extra travel time in the hypothetical scenario is given by $b_{i}^{P}>0$ and varies randomly across individuals:

$$
U_{i, j}^{k}=\alpha^{k}+\theta p_{i}+\sum_{j=0}^{J} \beta_{j} c_{j}^{k}\left(t_{i}+b_{i}^{k}\right)+\delta X_{i}+\varepsilon_{i}^{k}
$$

Note that in the actual state $(k=A), b_{i}^{A}=0$ and the utility in (6) collapses to the baseline given in (1). Moreover, we assume that the utility cost of travel time does not vary accross actual and hypothetical states of nature $\left(\beta_{j}=\beta_{j}^{A}=\beta_{j}^{P}\right)$. By contrast, the constant $\alpha^{k}$ is allowed to differ. This enables us to control for a potential tendency of individuals to prefer the hypothetical scenarios, conditional on any proposed improvements of travel conditions.

This formulation implies that if an individual accepts the contingent

\footnotetext{
${ }^{9}$ An alternative would be to estimate the marginal willingness to pay for all pairs of reference and hypothetical densities on the basis of equation (3). However, sample sizes for the 21 pairs would be too small, see appendix (7.1).
} 
scenario, i.e. prefers $U_{i}^{P}$ over $U_{i}^{A}$, we have:

$$
\begin{aligned}
\operatorname{Prob}(\text { Accept }) & =\operatorname{Prob}\left(U_{i, j}^{P}>U_{i, j}^{A}\right) \\
& =\Phi_{\varepsilon}\left[\alpha^{*}+\sum_{j=0}^{J} \beta_{j}^{*}\left(c_{j}^{P} T_{i}^{P}-c_{j}^{A} T_{i}^{A}\right)\right]
\end{aligned}
$$

where $T_{i}^{k} \equiv\left(t_{i}+b_{i}^{k}\right), \sigma_{\varepsilon}^{2}$ the variance of the differenced error term $\varepsilon=\varepsilon_{i}^{P}-\varepsilon_{i}^{A}$ and $\Phi_{\varepsilon}$ the cumulative density function of $\varepsilon$. We normalize the differenced parameter $\alpha^{*}=\frac{\alpha^{P}-\alpha^{A}}{\sigma_{\varepsilon}^{2}}$ and the time marginal disutility $\beta_{j}^{*}=\frac{\beta_{j}}{\sigma_{\varepsilon}^{2}}$.

In this framework, the value of comfort in situation $j$ is described by the coefficient $\beta_{j}^{*}$. The marginal rate of substitution between one minute of transport with comfort level $j$ and one minute with the reference comfort level $(j=0)$ is then given by the ratio of any two coefficients $\beta_{j}^{*}$ and $\beta_{0}^{*}$.

We can test the restriction that congestion costs do not depend on individual characteristics $\left(\delta=\delta^{A}=\delta^{P}\right.$ in equation (6)). We write $\delta$ as a function of trip duration $\delta=\delta_{1} X_{i}+\delta_{2, j} X_{i} t_{i}$, such that the utility function used to evaluate the bid is given as:

$$
U_{i, j}^{k}=\alpha^{k}+\theta p_{i}+\sum_{j=0}^{J} c_{j}^{k}\left(\beta_{j}+\delta_{2, j} X_{i}\right)\left(t_{i}+b_{i}^{k}\right)+\delta_{1} X_{i}+\varepsilon_{i}^{k},
$$

We can test whether individual characteristics $X_{i}$ influence preferences for less crowded travel conditions by writing:

$$
\begin{aligned}
\operatorname{Prob}(\text { Accept }) & =\operatorname{Prob}\left(U_{i, j}^{P}>U_{i, j}^{A}\right) \\
& =\Phi_{\varepsilon}\left[\alpha^{*}+\sum_{j=0}^{J} \beta_{j}^{*}\left(c_{j}^{P} T_{i}^{P}-c_{j}^{A} T_{i}^{A}\right)+\delta_{1}^{*} X_{i}+\sum_{j=0}^{J} \delta_{2, j}^{*}\left(c_{j}^{P} T_{i}^{P}-c_{j}^{A} T_{i}^{A}\right) X_{i}\right],
\end{aligned}
$$

where $\delta_{z, j}^{*}=\frac{\delta_{z, j}^{P}-\delta_{z, j}^{A}}{\sigma_{\varepsilon}^{2}}$ for $z \in\{1,2\}$. The marginal disutility of travel duration at comfort level $j$ is now given by $\beta_{j}^{*}+\delta_{2, j}^{*} X_{i}$, thus varying with individuals' characteristics $X_{i}$. The parameter $\delta_{2, j}^{*}$ may be considered a sensitivity premium. 


\subsection{Estimation methods}

By assessing which factors induce individuals to accept a given bid, we estimate the determinants of the marginal disutility of travel time. The probabilistic choices of accepting the bids as expressed by equations (7) and (10) could be estimated with standard probit or logit models, depending on assumptions made on the error term $(\varepsilon)$. Furthermore, every individual is confronted with two bids and we need to consider how to treat the relation between answers to the first and second round of bidding. The double-bounded model introduces interdependency between rounds because the follow-up question is conditioned on individuals' answer to the first bid.

First, since the strategy is to increase the precision of the estimates (Hanemann et al. (1991)) by increasing the bids for individuals willing to accept the first bid (leading to potential "Yes-No" sequences of bid acceptance) or decrease the bid for individuals not willing to accept the first bid ("No-Yes" sequences), we may expect a negative correlation across bids as a result of the questioning technique.

Second, individual time invariant heterogeneity in answering the two bids would lead to a positive correlation across questions - individuals with a high willingness to pay for comfort (conditional on the other variables in the model) would do so in both the first and second rounds of bidding.

Third, many CVM studies applied to the valuation of environmental goods have shown that psychological factors may affect the second answers due to "starting point" biases (Haab and McConnel (2003)). In this case, the double-bounded design of the survey is itself responsible for possible socalled "anchoring, shift and framing" biases (Flachaire and Hollard (2007)).

Any of these effects would violate the assumption of independently and identically distributed answers, thus leading to biased estimates of $\beta_{j}^{*}$. Thus we focus on estimation methods that take into account the relationship between answers to the two rounds.

Our first estimator is the bivariate probit model, first implemented in evaluating non-market goods by Cameron and Quiggin (1994). This model estimates coeffients for both rounds of questions separately but assumes that the distribution of the error terms $\varepsilon$ across the two rounds is bivariate normal. No (further) restriction is posed on the covariance structure of the error 
terms and the degree of dependency is measured by the correlation coefficient between the error terms $(\rho)$.

Our second estimator focuses on the interdependence between the two bidding rounds induced by individual unobserved characteristics. We set up the data as a panel and assume that individual time-invariant characteristics are not correlated with duration of the trips, that is, assume a random effects framework. This implies a restriction on the correlation of the error terms across rounds (necessarily positive). Since the two rounds of bidding are assumed to originate from the same vector of parameters, only one set of parameter estimates is generated by this estimator. The random effects estimators was first applied to the analyzis of the double-bounded model by Alberini et al. (1997).

Both estimators provide us with measures of intra-class correlation, i.e. of the change in the propensity of the same individual to accept or reject a bid conditional on their answer to the first bid. The estimated parameter $(\rho)$ in the random effects model is the proportion of total variance accounted for by unobserved individual heterogeneity $\left(\rho \equiv \frac{\sigma_{u}^{2}}{\sigma_{\varepsilon}^{2}}\right)$. As noted, the bivariate probit estimates the correlation between the errors in the first and second round (assuming normality). If the error structure assumed by the random effects specification is correct, the interdependence across bidding rounds can be given by an additive separable component $u$ ( $\operatorname{such}$ that $\varepsilon_{i, t}=\varepsilon_{i, t}^{*}+u_{i}$ ), the two measures are equal since:

$$
\begin{aligned}
\rho_{\varepsilon_{1}, \varepsilon_{2}} & =\frac{\operatorname{cov}\left(\varepsilon_{1}, \varepsilon_{2}\right)}{\sigma_{\varepsilon_{1}} \sigma_{\varepsilon_{2}}} \\
& =\frac{\operatorname{cov}\left(\varepsilon_{1}^{*}+u, \varepsilon_{2}^{*}+u\right)}{\sigma_{\varepsilon_{1}^{*}+u} \sigma_{\varepsilon_{2}^{*}+u}} \\
& =\frac{\sigma_{u}^{2}}{\sigma_{\varepsilon^{*}}^{2}+\sigma_{u}^{2}} \\
& =\frac{\sigma_{u}^{2}}{\sigma_{\varepsilon}^{2}} \equiv \rho,
\end{aligned}
$$

where we use the random effects assumption and assume equal variance of $\varepsilon_{1}^{*}$ and $\varepsilon_{2}^{*}$. 


\subsection{Results}

Table (7) presents the effects of different levels of passenger density on the probability of accepting longer travel times for less crowded commuting conditions, i.e. on the disutility of trip duration. All levels of passenger density greater than 1 passenger per square metre significantly decrease individual utility (at the 1\% level). This suggests that whilst PT users prefer having some people around them rather than facing empty vehicles, the utility cost of travel time $\beta_{j}^{*}$ increases in crowded situations.

The estimated value of $\rho$ shows both in the bivariate and the random effects estimation that users' answers to the first and second bids are not independent. This is consistent with the observed sequences of answers, with more users accepting or rejecting twice the contingent scenarios (see appendix (7.2)). If we neglect potential starting point biases, a positive correlation of the error terms across answers is also prima facie evidence of individual effects being more important than the effect of bid sequencing. Thus we believe that the restriction embodied in the random effects model may be warranted. In what follows we mainly focus on the random effects results ${ }^{10}$. As graph (2) shows, travel times are more costly in the random effects framework than in the bivariate probit estimates.

Focusing on the random effects results is only sensible if the parameter estimates for the two rounds are not significantly different. Indeed, answers to double-bounded models have shown large differences accross rounds, thus questioning the relevance of CVM to assess non-market goods (Flachaire and Hollard (2007), Haab and McConnel (2003)). In our bivariate probit results, the time disutilities estimated from the second bids lie within the confidence intervals of those obtained from the first round bids (see appendix (7.4)). Since confidence intervals overlap throughout the range of estimated crowding costs, our results indicate that whilst biases may exist ${ }^{11}$, they do not influence estimated values of $\beta_{j}^{*}$. Furthermore, we suggest that the degree of realism of the hypothetical scenario plays in our favour here - how long to wait for a less congested train is easier to assess than the utility of not having an oil spill near ones place of residence.

\footnotetext{
${ }^{10}$ Both the Schwarz (BIC) and Aikaki (AIC) information criteria for model selection indicate that the random effects specification is preferred.

${ }^{11}$ Note also that the constant specific term is highly significant, both in the bivariate and the random effects probit models. It is thus important to control for PT users' unexplained tendency to consent to proposed bids.
} 
Table 7: Discrete choices estimates

\begin{tabular}{|c|c|c|c|}
\hline & \multicolumn{2}{|c|}{ Bivariate Probit } & \multirow{2}{*}{$\begin{array}{c}\text { Random Effects } \\
\text { Both Bids }\end{array}$} \\
\hline & First Bid & Second Bid & \\
\hline $\begin{array}{l}\text { Marginal disutility of trip } \\
\text { duration by crowding: }\end{array}$ & & & \\
\hline 0 pass $/ \mathrm{m}^{2}$ & $\begin{array}{c}-0.124^{* * *} \\
(0.009)\end{array}$ & $\begin{array}{c}-0.148^{* * *} \\
(0.010)\end{array}$ & $\begin{array}{c}-0.200^{* * *} \\
(0.025)\end{array}$ \\
\hline 1 pass $/ \mathrm{m}^{2}$ & $\begin{array}{c}-0.116^{* * *} \\
(0.010)\end{array}$ & $\begin{array}{c}-0.155^{* * *} \\
(0.011)\end{array}$ & $\begin{array}{c}-0.200^{* * *} \\
(0.025)\end{array}$ \\
\hline $2 \operatorname{pass} / \mathrm{m}^{2}$ & $\begin{array}{c}-0.126^{* * *} \\
(0.010)\end{array}$ & $\begin{array}{c}-0.159^{* * *} \\
(0.011)\end{array}$ & $\begin{array}{c}-0.210^{* * *} \\
(0.026)\end{array}$ \\
\hline $2.5 \mathrm{pass} / \mathrm{m}^{2}$ & $\begin{array}{c}-0.141^{* * *} \\
(0.010)\end{array}$ & $\begin{array}{c}-0.177^{* * *} \\
(0.011)\end{array}$ & $\begin{array}{c}-0.235^{* * *} \\
(0.028)\end{array}$ \\
\hline 3 pass $/ \mathrm{m}^{2}$ & $\begin{array}{c}-0.157^{* * *} \\
(0.012)\end{array}$ & $\begin{array}{c}-0.185^{* * *} \\
(0.012)\end{array}$ & $\begin{array}{c}-0.253^{* * *} \\
(0.031)\end{array}$ \\
\hline 4 pass $/ \mathrm{m}^{2}$ & $\begin{array}{c}-0.174^{* * *} \\
(0.012)\end{array}$ & $\begin{array}{c}-0.206^{* * *} \\
(0.014)\end{array}$ & $\begin{array}{c}-0.281^{* * *} \\
(0.034)\end{array}$ \\
\hline 6 pass $/ \mathrm{m}^{2}$ & $\begin{array}{c}-0.193^{* * *} \\
(0.015)\end{array}$ & $\begin{array}{c}-0.234^{* * *} \\
(0.016)\end{array}$ & $\begin{array}{c}-0.315^{* * *} \\
(0.039)\end{array}$ \\
\hline Constant & $\begin{array}{c}0.575^{* * *} \\
(0.083) \\
\end{array}$ & $\begin{array}{c}0.763^{* * *} \\
(0.084)\end{array}$ & $\begin{array}{c}0.980^{* * *} \\
(0.176)\end{array}$ \\
\hline$\rho$ & $\begin{array}{c}0.601^{* *} \\
(0.045)\end{array}$ & & $\begin{array}{c}0.557^{*} \\
(0.065)\end{array}$ \\
\hline $\mathrm{AIC}$ & $3,065.6$ & & $1,543.8$ \\
\hline $\mathrm{BIC}$ & $3,153.9$ & & $1,590.5$ \\
\hline Observations & 668 & 668 & 668 \\
\hline
\end{tabular}

Note: ${ }^{*}: p<0.10 ;{ }^{* *}: p<0.05 ;{ }^{* * *}: p<0.01$. 


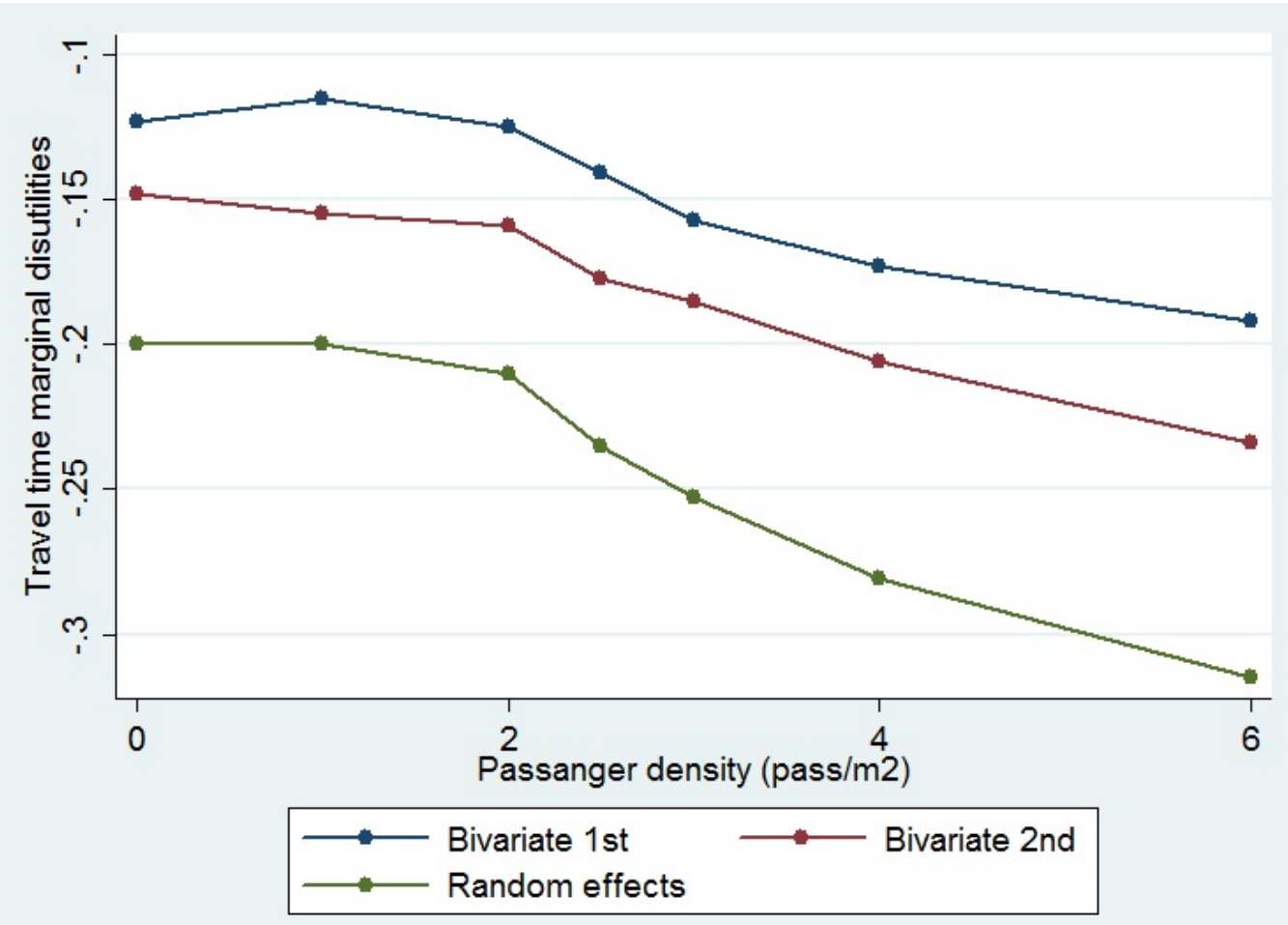

Figure 2: Travel time marginal disutilities 
Finally, we test the restriction that crowding costs are independent of individual observed characteristics (i.e. $\delta_{2, j}^{*}=0$ ). We thus estimate equation (10), introducing interactions of travel time with various individual characteristics (age, gender, reason for trip, place of residency, line, time of day, car ownership, line daily usage, income, door-to-door travel time). We tested different characteristics $X_{i}$ and find significant sensitivity premia $\left(\delta_{2, j}^{*}\right)$ only for the time of day (see table (16) in the appendix) - for all levels of comfort considered, travel time appears to be more costly for morning commuters. However, the point estimate of the sensitivity premium for the 6 pass $/ \mathrm{m}^{2}$ situation is lower than the corresponding value for $4 \mathrm{pass} / \mathrm{m}^{2}$ (although table (8) indicates that the difference is not significant). This produces a lower travel time marginal disutility during morning peaks for the former situation. Moreover, the dummy Morning alone, i.e. not interacted, does not affect individuals' answers $\left(\hat{\delta}_{1}^{*}=0\right)$. Figure (5) in the appendix (7.4) contrasts the marginal disutility of crowding in the morning and evening peaks.

\subsection{The time multipliers}

With these results, we can now calculate time multpliers $(\mathrm{Tm})$ across different levels of comfort. In order to compute the $T m$, one first has to choose a reference level of congestion, i.e. a denominator. We could use the empty subway as benchmark (with 0 pass $/ \mathrm{m}^{2}$ ). However, calculating PT crowding costs with respect to empty subways appears inconsistent with the social utility of infrastructure ${ }^{12}$. Therefore we use the $1 \mathrm{pass} / \mathrm{m}^{2}$ situation, with 2 seats (out of 8 ) still available on the showcard ${ }^{13}$.

In table (8), we find that the value of $T m$ ranges from 1.05 (for crowding of 2 pass $\left./ \mathrm{m}^{2}\right)$ to $1.57\left(6\right.$ pass $\left./ \mathrm{m}^{2}\right)$ when using our preferred random effects estimator. This implies that travellers are indifferent between spending 1 minute in worse travel conditions and being seated for 1.6 minutes $^{14}$. Figure (3) illustrates the increasing relationship between $T m$ and in-vehicle passanger density. As made clear, standard errors of estimated Tm become

\footnotetext{
${ }^{12}$ The same is true for road congestion, where analyses typically calculate congestion costs with reference to an empty road (Small and Verhoef (2007)).

${ }^{13}$ Note also that the bivariate probit estimates from the first round suggest that PT users prefer this situation over the situation with no other passengers.

${ }^{14}$ Estimates from the first round of bidding in the bivariate probit provide slightly higher crowding valuations: the maximum $T m$ is 1.67 for 6 pass $/ \mathrm{m}^{2}$ and the minimum $T m 1.09$ at 2 pass $/ \mathrm{m}^{2}$. In the second round bidding, the Tm ranges from 1.03 to 1.51 .
} 
Table 8: Time multipliers (random effects estimates)

\begin{tabular}{|c|c|c|c|c|}
\hline Density & $\mathbf{T m}$ & $\mathbf{T m}(\mathbf{m o r})$ & $\mathbf{T m}(\mathbf{e v e})$ & Disutility of time(m/e) \\
& & & & \\
\hline $0 \mathrm{pass} / \mathrm{m}^{2}$ & 1.00 & 1.02 & 0.93 & 1.68 \\
& $(0.91-1.08)$ & $(0.93-1.12)$ & $(0.78-1.08)$ & $(1.13-2.24)$ \\
$1 \mathrm{pass} / \mathrm{m}^{2}$ & 1.00 & 1.00 & 1.00 & 1.53 \\
& & & & $(1.02-2.03)$ \\
$2 \mathrm{pass} / \mathrm{m}^{2}$ & 1.05 & 1.06 & 1.06 & 1.52 \\
& $(0.97-1.13)$ & $(0.96-1.15)$ & $(0.91-1.21)$ & $(1.06-1.97)$ \\
$2.5 \mathrm{pass} / \mathrm{m}^{2}$ & 1.18 & 1.19 & 1.18 & 1.54 \\
& $(1.07-1.28)$ & $(1.07-1.31)$ & $(0.99-1.36)$ & $(1.08-2.00)$ \\
$3 \mathrm{pass} / \mathrm{m}^{2}$ & 1.26 & 1.24 & 1.29 & 1.47 \\
& $(1.13-1.39)$ & $(1.10-1.38)$ & $(1.05-1.53)$ & $(1.01-1.92)$ \\
$4 \mathrm{pass} / \mathrm{m}^{2}$ & 1.40 & 1.52 & 1.31 & 1.78 \\
& $(1.25-1.56)$ & $(1.33-1.71)$ & $(1.06-1.56)$ & $(1.22-2.33)$ \\
$6 \mathrm{pass} / \mathrm{m}^{2}$ & 1.57 & 1.46 & 1.67 & 1.34 \\
& $(1.35-1.80)$ & $(1.20-1.73)$ & $(1.27-2.06)$ & $(0.89-1.79)$ \\
\hline
\end{tabular}

Source: Authors' calculations.

Notes: $T m(m o r)$ refers to the time multiplier for the morning peak, Tm(eve) for the evening peak, Disutilityoftime(m/e) gives the relative disutility of travel time, i.e. the marginal rate of substitution of travel time between morning and evening peaks (at given levels of density) using random effects probit. Confidence intervals (estimated with the delta method) are in brackets. 


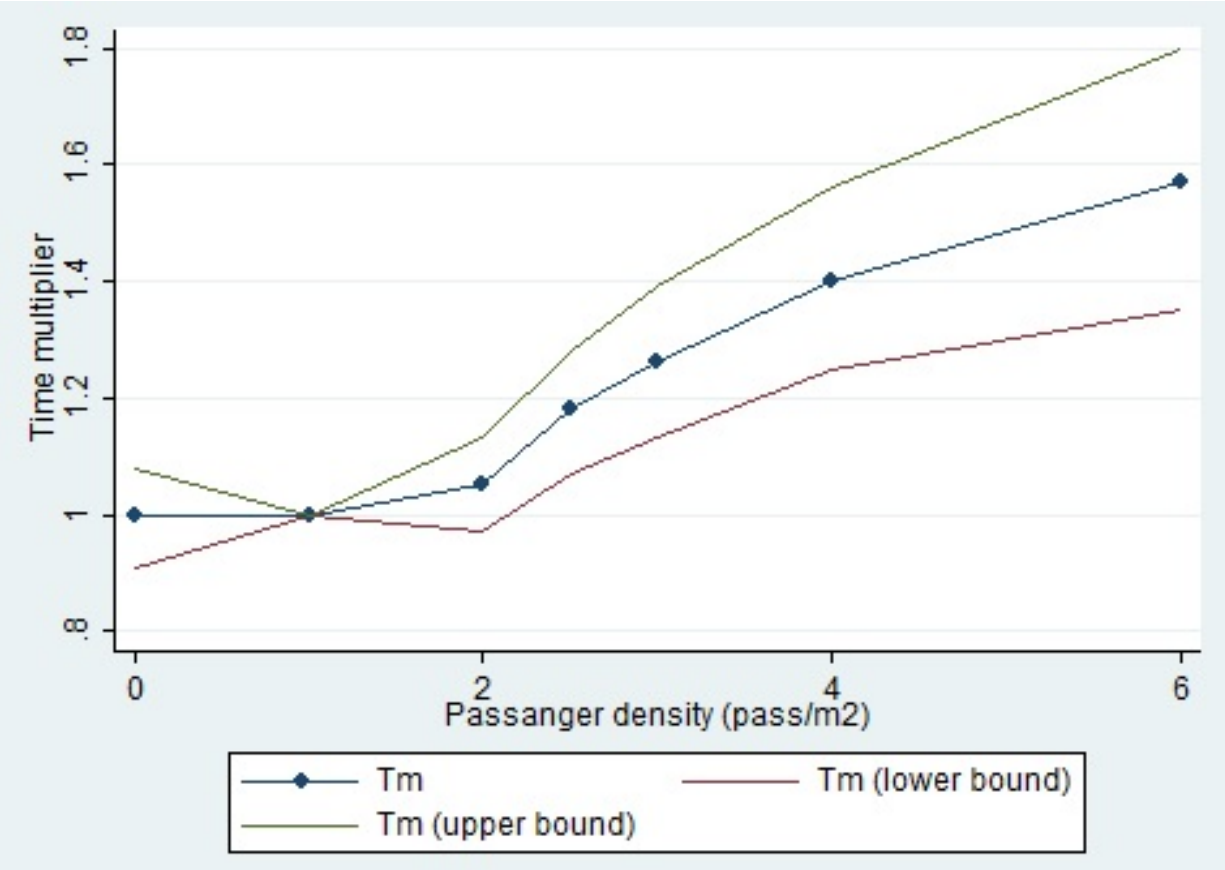

Figure 3: Time multipliers and 95\% confidence interval (estimated by the delta method)

higher with more congested journeys.

We now compare the value of $T m$ in the morning and evening peaks. For the evening peaks' trips we find a clear increasing relationship between density and willingness to trade travel time (the maximum Tm is 1.67 at 6 pass $/ \mathrm{m}^{2}$ ). For the morning rush hour, the increase is similar but slightly less marked and the point estimate of $T m$ drops to 1.46 for the 6 pass $/ \mathrm{m}^{2}$ situation, below the value associated with the $4 \mathrm{pass} / \mathrm{m}^{2}$ situation.

Finally, we can also use our estimates to compare the marginal disutility of travel time in the morning and evening peaks. Contrasting the two periods, the marginal rate of substitution between one minute during morning and evening peaks (for a given level of comfort) ranges from 1.34 to 1.78. This implies that individuals are willing to trade one minute of morning commute with up to 1.78 minutes of commute in the evening. This morning peak premium may be seen as a proxy for the higher scheduling costs in the 
morning linked to late arrivals at work and earlier departures from home (Arnott et al. (1990); de Palma et al. (2011)).

Reported $T m$ valuations appear to be consistent with the literature presented in section (2.2), even if the maximum values are somewhat lower than those of Debrincat et al. (2006) or Whelan and Crockett (2009). It is also noticeable that the rule of thumb used in France to take into account PT congestion is remarkably close to these results (Commissariat Général du Plan (2001), Ministère de l'Equipement (2005)). Above all, these results stress that ignoring the crowding effect may significantly alter the analyses of PT usage costs.

\section{$5 \quad$ Policy Implications}

An influential way of presenting congestion costs on roads uses speed-flowdensity relationships that describe infrastructures' capacity (Small and Verhoef (2007)). Similarly, we express the $T m$ as a function of in-vehicle passanger density. Ideally, this information could be used to design pricing and supply schedules in a PT network (Jara-Diaz and Gschwender (2003), de Palma et al. (2011), Prud'homme et al. (2012)). In line with Whelan and Crockett (2009), we test a simple linear form. We also normalize to have the one-passenger-situation as origin $\left(c_{j}=1\right.$ pass $/ \mathrm{m}^{2}, T m=1$, see figure (3)). Using the values from the random effects model, we estimate a coefficient of 0.11 for the linearised relationship between the time multiplier and the level of density measured in pass $/ \mathrm{m}^{2}\left(d_{j}\right.$, such that $\left.c_{1}=1, \ldots, J \Rightarrow d=1,2, \ldots, J\right)$.

$$
\operatorname{Tm}\left(d_{j}\right)=d_{0}+0.11 d_{j},
$$

where $d_{0}=1$.

\subsection{The Generalized Cost of Public Transport}

We can now add crowding costs to the traditional presentation of generalized PT costs $\left(G C\left(d_{j}\right)\right)$ in terms of money and time. Defining $w$ as the opportunity cost of trip duration, we apply the time multiplier $\operatorname{Tm}\left(d_{j}\right)$ taking into account crowding costs and in-vehicle travel time $\left(t_{i}\right)$ as proposed by Jara-Diaz and Gschwender (2003) and Feifei and Haicheng (2011):

$$
G C\left(d_{j}\right)=p_{i}+w t_{i} \operatorname{Tm}\left(d_{j}\right) .
$$

The figures in table (9) use average values of in-vehicle travel time, expected density and time opportunity cost (see section (3)). We also assume 
that $p_{i}=p=0.50 €$ per trip which approximately corresponds to the average private cost incurred by passengers taking into account public and employer transport subsidies. Furthermore we use a single $T m$-density relationship and do not distinguish morning from evening peaks. According to these results, the generalized cost of Paris subway usage during peak periods rises to $€ 3.07 /$ trip compared to $€ 2.42 /$ trip when seating in trains is available. Neglecting PT crowding costs implies underestimating by $27 \%$ the welfare costs of transport activities during rush hours ${ }^{15}$.

Table 9: Generalized costs, time multipliers and willingness to pay

\begin{tabular}{|l|c|c|c|c|c|}
\hline & Total & Line 1 & Line 4 & Morning & Evening \\
\hline GC(peaks) (eu/pass) & 3.07 & 4.18 & 2.35 & 3.11 & 3.06 \\
GC(seat) (eu/pass) & 2.42 & 3.15 & 1.84 & 2.47 & 2.38 \\
\hline Tm & 1.34 & 1.39 & 1.30 & 1.32 & 1.36 \\
WTP (min/pass) & 3.3 & 4.5 & 2.4 & 3.0 & 3.6 \\
WTP (eu/pass) & 0.66 & 1.04 & 0.41 & 0.63 & 0.68 \\
\hline
\end{tabular}

Source: Authors' calculations.

Whilst the $G C\left(d_{j}\right)$ strongly differs between lines 1 and 4 (due to longer trip durations and a higher time opportunity cost on the former), we do not observe any difference between morning and evening peaks. Moreover, the average $T m$ ranges from 1.30 (on line 4) to 1.39 (on line 1), with a mean value of 1.34. This corresponds to an increase in time value by $€ 0.07 / \mathrm{min}$, i.e. $€ 4.01 / \mathrm{h}$, with an average time opportunity cost of $€ 12 / \mathrm{h}$. Using equation (5) in section (2), the average $W T P$ is equal to $3.3 \mathrm{~min} /$ trip, i.e. $€ 0.66 /$ trip in monetary terms.

Using the estimates of $W T P$, we can calculate the welfare gains induced by a policy which reduces passenger density by $60 \%$ during peak periods. Assuming that $50 \%$ of the 750,000 daily trips in line 1 occur during peaks, we apply the monetarized $W T P(€ 1.04 /$ trip). On the basis of 300 days per year of commuting, we find a potential welfare benefit of $€ 117 \mathrm{~m}$. The same

\footnotetext{
${ }^{15}$ Estimates of the generalized costs are lower when using the objective density indicators (see table (5)). However, the difference is not as important as one might expect: $G C($ peaks $)=€ 2.91 /$ trip with the count data and $G C($ peaks $)=€ 2.78 /$ trip with the data from the PT operator. Compared to the benchmark situation, this still implies a $15-20 \%$ increase in the generalized cost of PT usage.
} 
calculation for line 4 (with $W T P=€ 0.41 /$ trip and 670,000 daily users) gives a figure of $€ 41 \mathrm{~m}$. Assuming that the travel time and the time opportunity cost from our sample are representative for the population of PT users, we can extend the analysis to the whole network of Paris subways. Based on $1,479 \mathrm{~m}$ trips realized in 2009, i.e. $739.5 \mathrm{~m}$ during peak periods (Syndicat des Transports de la Région Ile-de-France (2009)), and applying an average WTP of $€ 0.66 /$ trip results in potential benefits of $€ 488 \mathrm{~m}$.

We can also use the $T m$-density relationship to estimate the evolution of the generalized cost of subway usage in Paris. According to the statistics provided in table (1), passanger density in the Paris subway network grew by $10 \%$ over $2000-2009$ (considering peak and off-peak periods). Using our survey data and average densities in table $(1)$, we find a $G C\left(d_{j}\right)$ difference of $€ 0.23$ /trip. Applying the latter result to $1,479 \mathrm{~m}$ trips performed in 2009 (Syndicat des Transports de la Région Ile-de-France (2009)), we obtain a rise of $€ 340 \mathrm{~m}$ in the $G C\left(d_{j}\right)$ for all Paris subway users. If we restrict calculations to individuals who were already subway users in 2000, the additionnal congestion costs in subways are $€ 283 \mathrm{~m}$. This growing crowding in trains appears as costly as the time losses induced by the municipal policy of road space narrowing. For comparison, the increase in time costs due to the $10 \%$ decrease in travel speed in Paris through 2000-2009 can be estimated to have cost drivers $€ 294 \mathrm{~m}^{16}$.

Urban transport policies have understandably been attempting to increase the modal share of PT for environmental reasons and to preserve the attractiveness of city centres. The results here indicate that welfare costs are imposed on existing users of PT unless additional investments are made. Our figures are in line with growing complaints of commuters in the city centre of Paris and the subjective perception of travel activities (Li (2003)).

\subsection{The subway crowding externality}

Once we have recognized that the $G C\left(d_{j}\right)$ is significantly influenced by the level of PT crowding, the existence of a congestion externality should be

\footnotetext{
${ }^{16}$ Based on updated figures from 2007, around 4,900m pkm were driven in Paris in 2009 (Observatoire de la mobilité de la ville de Paris (2009), Kopp (2011)). Over 2000-2009, the average car speed in Paris decreased by $10 \%(17.4 \mathrm{~km} / \mathrm{h}$ and $15.6 \mathrm{~km} / \mathrm{h}$, Observatoire de la mobilité de la ville de Paris (2009)), which means an additional 0.3 minute to perform 1 kilometer. Assuming that car users have the same time opportunity cost as subway users we find $€ 0.06 / \mathrm{km}$. This yields $€ 294 \mathrm{~m}$ in additional congestion costs.
} 
explicited. In fact, this non-market interaction generates an external cost $\left(M C\left(d_{j}\right)\right)$ and calls for public interventions minimising the social cost of subway usage $\left(S C\left(d_{j}\right)\right)$. Following a Pigouvian framework, largely used to study road congestion (Small and Verhoef (2007)), we can write:

$$
S C\left(d_{j}\right)=G C\left(d_{j}\right)+M C\left(d_{j}\right)=G C\left(d_{j}\right)+\frac{\partial G C\left(d_{j}\right)}{\partial d_{j}} d_{j}
$$

Using our relationship between the time multiplier and passenger density, we distinguish the marginal cost of subway congestion according to the levels of comfort in trains. Table (10) shows that the average external cost in the Paris subway is $€ 0.63$ /pass (using the average expected density of $3 \mathrm{pass} / \mathrm{m}^{2}$ ). In addition, we observe that the social cost of PT usage becomes quite large for very crowded conditions. Thus, the $S C\left(d_{j}\right)$ reaches $€ 4.96 /$ pass when 6 pass $/ \mathrm{m}^{2}$ crowd the trains, for a $G C\left(d_{j}\right)$ equal to $€ 3.69 /$ pass. This should be compared to the benchmark situation, i.e. $€ 2.42 /$ trip.

Table 10: Generalized, marginal and social costs of PT usage

\begin{tabular}{|c|c|c|c|c|}
\hline Density & $\begin{array}{c}\mathbf{G C}\left(d_{j}\right) \\
(\mathrm{eu} / \mathrm{pass})\end{array}$ & $\begin{array}{c}\mathbf{M C}\left(d_{j}\right) \\
(\mathrm{eu} / \mathrm{pass})\end{array}$ & $\begin{array}{c}\mathbf{S C}\left(d_{j}\right) \\
(\mathrm{eu} / \mathrm{pass})\end{array}$ & $\begin{array}{c}\mathbf{M C} / \mathbf{S C} \\
(\%)\end{array}$ \\
\hline $0 \mathrm{pass} / \mathrm{m}^{2}$ & 2.42 & 0.00 & 2.42 & 0 \\
$1 \mathrm{pass} / \mathrm{m}^{2}$ & 2.42 & 0.00 & 2.42 & 0 \\
$2 \mathrm{pass} / \mathrm{m}^{2}$ & 2.84 & 0.42 & 3.26 & 13 \\
$2.5 \mathrm{pass} / \mathrm{m}^{2}$ & 2.95 & 0.53 & 3.48 & 15 \\
$3 \mathrm{pass} / \mathrm{m}^{2}$ & 3.05 & 0.63 & 3.68 & 17 \\
$4 \mathrm{pass} / \mathrm{m}^{2}$ & 3.26 & 0.84 & 4.10 & 20 \\
$6 \mathrm{pass} / \mathrm{m}^{2}$ & 3.69 & 1.27 & 4.96 & 26 \\
\hline
\end{tabular}

We can compare the valuation of the crowding externality to other nonmarket interactions linked to urban transportation (road congestion, accidents, noise, local pollutants, GHG). Since the values provided by the Handbook on estimation of external costs in the transport sector (Malibach et al. (2008), see also Leurent et al. (2009)) are given in kilometric terms, we divide the marginal cost found previously for subways ( $€ 0.63 /$ pass at $3 \mathrm{pass} / \mathrm{m}^{2}$ ) by the average distance of a trip performed in the Paris network (3.8 kilometres in our sample, see table (3)). Thus, we obtain a kilometric cost of 
$€ 0.17$. As indicated in table (11), the marginal cost of subway congestion is $40 \%$ of the corresponding value for road congestion in Paris $(€ 0.43 / \mathrm{km}$ using Leurent et al. (2009)) - but exceeds estimates of the costs of environmental and physical externalities.

Table 11: Urban transport marginal costs

\begin{tabular}{|l|c|c|c|c|c|c|}
\hline & $\begin{array}{c}\text { Subway } \\
\text { congestion }\end{array}$ & $\begin{array}{c}\text { Road } \\
\text { congestion }\end{array}$ & $\begin{array}{c}\text { Cars } \\
\text { accidents }\end{array}$ & $\begin{array}{c}\text { Local } \\
\text { pollutants }\end{array}$ & $\begin{array}{c}\text { Cars } \\
\text { noise }\end{array}$ & $\begin{array}{c}\text { GHG } \\
\text { emissions }\end{array}$ \\
\hline$M C(\mathbf{e u} / \mathbf{k m})$ & 0.17 & 0.43 & 0.07 & 0.02 & 0.01 & 0.01 \\
\hline
\end{tabular}
tion.

The relevance of the crowding externality could be underlined by conducting costs-benefits analyses of transport investments, such as pro-bike, bus or streetcar policies. Taking into consideration the benefits of subway decongestion may significantly alter the Net Present Value $(N P V)$ and the Internal Rate of Return $(I R R)$ of new projects. Note also that the $M C\left(d_{j}\right)$ figures in table (10) could be used as proxies for a policy of Pigouvian taxation aiming at internalizing the social cost of subway usage ${ }^{17}$. Whereas fares do not vary by time of day in Paris, fares are increased by $30-70 \%$ during rush hours in the London underground network. To conclude this analysis, we show how crowding costs can be integrated in cost-benefit analyses using the estimates provided here.

\subsection{Investment in capacities}

Since late 2012, line 1 runs without drivers. With this new system, the PT operator seeks to improve reliability and service quality by finetuning the supply of line 1 in response to varying demand. Does the initial investment of $€ 629 \mathrm{~m}-€ 479 \mathrm{~m}$ for the new rolling stock and $€ 150 \mathrm{~m}$ for installations in platforms (automatic gates essentially, see Régie Autonome des Transports Parisiens (2011)) - correspond to a socially desirable policy?

We identify three main effects of line 1 automation on the well-being of subway users:

\footnotetext{
${ }^{17}$ It should be noted that our cost estimates are not equivalent to the optimal tax level, which would cover the - lower - level of crowding costs at the optimal level of PT usage.
} 
1. The average commercial speed of line 1 will increase by $10 \%$ (Régie Autonome des Transports Parisiens (2011)), during both peak and non-peak periods. Considering our 11.5 minutes figure for rush hours (see table (3)), in-vehicle travel time will drop to 10 minutes.

2. During peaks, line 1 automation will increase trains' frequency by $20 \%$ : from intervals of 1 minute 45 seconds currently to 85 seconds (Régie Autonome des Transports Parisiens (2011)), i.e. 10 seconds saved on waiting time ${ }^{18}$.

3. Assuming a constant peak demand for line 1, trains' higher frequency implies that the (reduced) in-vehicle time is consumed with more comfortable travel conditions. Thus, the average density $\left(3.5 \mathrm{pass} / \mathrm{m}^{2}\right)$ will decrease by $20 \%$ decrease falling to 2.9 pass $/ \mathrm{m}^{2}$.

We can use our results to compute the corresponding welfare changes. The value of the saved waiting times on platforms is doubled vis-à-vis invehicle values - as recommanded by the Boiteux report (Commissariat Général du Plan (2001)). Reduced waiting times then generate a gain of $€ 8.6 \mathrm{~m}$ for line 1 commuters (on the basis of 375,000 trips during peaks and 300 days per year). Above all, automation leads to a reduction by $€ 73.1 \mathrm{~m}$ per year in generalized costs due to improved speed and comfort during peaks $(€ 0.65 /$ trip saved). Assuming that the in-vehicle travel time does not vary accross peak and off-peak periods, non commuters are finally $€ 38.8 \mathrm{~m}$ better-off. Thus nearly one half $(47 \%)$ of the $73.1 \mathrm{~m}$ gain accrues as a result of lower crowding costs and is currently not taken into account in cost benefit analyses. Taken jointly, the annual benefits for line 1 users induced by automation reach $€ 120.5 \mathrm{~m}$.

In order to calculate the $N P V$ of the investment, we compare the sum of future discounted benefits (using a $4 \%$ discount rate, as officialy recommended in France, Commissariat Général du Plan (2005)) to the initial cost of $€ 629 \mathrm{~m}$. Given the social cost of raising public funds by taxation, French guidelines suggest augmenting public costs by a factor of 1.3 (Ministère de l'Equipement (2005)). Following these rules, the $N P V$ of line 1 automation is $€ 819.9 \mathrm{~m}$ over a 20 year horizon. This corresponds to the discounted value of the time resources saved by the project, net of the financial costs. The $I R R$ is $5.6 \%$, well above the $4 \%$ threshold considered as the minimal required level of profitability for transport projects in France. Therefore, the

\footnotetext{
${ }^{18}$ Assuming a uniform distribution of arrivals on platforms, mean waiting times will drop from 53 seconds to 43 seconds.
} 
automation of subway lines seems to be a good initiative.

Although this cost-benefit analysis cannot take into account all impacts, we consider our results to be robust. The potential rolling stocks effect thus appears small: according to commercial sources, the new carriages in line 1 offer approximately the same number of places as the old ones (720 places per train $)^{19}$. In addition, the $\mathrm{PT}$ operator promised unions that subway automation was not implemented in order to save labour, the most important element of operational costs. Finally, we assume a constant demand in line 1 whereas faster and more comfortable travel conditions may attract users from other services ${ }^{20}$. Given the linearity of the $T m$-passanger density relationship, benefits of lower density in other PT systems would perfectly compensate reduced comfort gains in line 1 .

\section{Conclusion}

Using new data from a survey of Paris subway users we find that crowding in public transport (PT) systems is a non-negligible factor affecting individuals' utility of trips.

Whereas the typical private monetary cost of a trip was $€ 0.50$, we found a monetized total trip cost of $€ 2.42$ for a seated passenger and around $€ 3.69$ under the most congested conditions. Our empirical results also allow us to approximate the marginal cost of subway crowding (€0.67/trip), a first-order urban externality, and to calculate the opportunity cost of transport time as a function of in-vehicle density (making the time multiplier a function of crowding). The value of travel time has to be increased by $34 \%$ in order to account for crowding during peaks in Paris subways.

Whilst models used to evaluate transport policies recognise the existence of PT crowding, typically the calibrations do not give significant weight to this factor. First, the design of PT networks needs to focus not only on the

\footnotetext{
${ }^{19}$ Moreover, the old carriages of line 1 have been moved on line 4 whose former trains counted 700 places, i.e. a $3 \%$ increase in line 4 supply, keeping trains' frequency constant.

${ }^{20} \mathrm{~A}$ close substitute on part of the line 1 is the regional train service RER A. Transporting $1 \mathrm{~m}$ passengers per day, it serves 5 stations in common with line 1 in central Paris (Nation, Gare de Lyon, Chatelet, Charles de Gaulle, La Défense) but provides different trip's caracteristics: connecting one of the pairs of stations takes around $15 \%$ less (in-vehicle) time with the RER A but is associated with a $30 \%$ higher passanger density.
} 
duration of trips, but also take into account crowding. Second, policies aimed at incentivising modal shift should fully factor in the effect of increased PT usage on current users. This underlines the necessity of accompanying modal shift policies focusing on restrictions for road transport with increased investment in $\mathrm{PT}$ infrastructure. We provide evidence on the additional costs of restrictive road policies and the additional benefits of PT infrastructure for the Parisian case. In an application to a recent infrastructure project we find additional gains resulting from lower crowding that are of similar magnitude to the benefits from faster services - but are largely ignored in economic apraisals.

Our results have been calculated using a contingent valuation methodology (CVM) that proposed a trade-off between (increased) travel time and (decreased) passenger density in vehicles. Individuals' stated preferences for less crowding appear robust and fairly consistent. The field survey we collected in lines 1 and 4 offers a rich empirical material calling for future research. A comparative study based on revealed preferences may also be of interest, verifying whether PT users trade as much time as they declare to in order to avoid crowded and uncomfortable trips.

\section{Acknowledgements}

This study was carried out without private or public funding. Survey design and data collection were made possible thanks to many volunteers. Among the main contributors, we would like to thank Mélanie Babès for survey design and data collection, Cécile Peillon for the design of the showcard, Cindy Balmat and Jérémy Boccanfuso. M. Locknar from the subway operator RATP was also of assistance. 


\section{Appendix}

\subsection{Description of contingent scenarios}

Table (12) gives the distribution of the hypothetical passenger density proposed to subway users as a function of PT users' current (expected) levels of density as indicated in the survey, i.e. the comfort reference point they expect to face in trains once the interview is finished.

Table 12: Hypothetical levels of comfort proposed to PT users

\begin{tabular}{|c|c|c|c|c|c|c|}
\hline Expected density $\left(\right.$ pass $/ \mathbf{m}^{2}$ ) & $\mathbf{1}$ & $\mathbf{2}$ & $\mathbf{2 . 5}$ & $\mathbf{3}$ & $\mathbf{4}$ & $\mathbf{6}$ \\
\hline $\begin{array}{c}\text { Hypothetical density: } \\
0 \text { pass } / \mathrm{m}^{2}\end{array}$ & $100.0 \%$ & $51.3 \%$ & $29.5 \%$ & $26.4 \%$ & $19.4 \%$ & $16.7 \%$ \\
$1 \mathrm{pass} / \mathrm{m}^{2}$ & & $48.7 \%$ & $31.4 \%$ & $21.6 \%$ & $20.9 \%$ & $8.3 \%$ \\
$2 \mathrm{pass} / \mathrm{m}^{2}$ & & & $38.6 \%$ & $31.1 \%$ & $21.6 \%$ & $16.7 \%$ \\
$2.5 \mathrm{pass} / \mathrm{m}^{2}$ & & & & $21.0 \%$ & $20.1 \%$ & $18.3 \%$ \\
$3 \mathrm{pass} / \mathrm{m}^{2}$ & & & & & $18.0 \%$ & $13.3 \%$ \\
$4 \mathrm{pass} / \mathrm{m}^{2}$ & & & & & & $26.7 \%$ \\
\hline
\end{tabular}

Source: Field survey on platforms.

Table (13) presents the distribution of the additional travel time that PT users must accept in order to enjoy more comfortable travel conditions. We targetted the distribution of answers found by Haywood and Koning (2012) during the first survey in line 1: only $5 \%$ of individuals accepted time bids above 15 minutes.

Table 13: Distribution of the first time bid proposed to PT users

\begin{tabular}{|l|c|c|c|c|c|c|}
\hline & $\mathbf{3}$ min. & $\mathbf{6}$ min. & 9 min. & $\mathbf{1 2}$ min. & $\mathbf{1 5}$ min. & 18 $\mathbf{~ m i n . ~}$ \\
\hline Distribution & $21.5 \%$ & $27.8 \%$ & $16.0 \%$ & $14.7 \%$ & $14.0 \%$ & $6.0 \%$ \\
\hline
\end{tabular}




\subsection{Descriptive statistics by sequence of bidding answers}

Table (14) shows that $25 \%$ of subway users accepted both time bids ("YesYes"). This proportion is higher for line 1 users (59\% of the "Yes-Yes" respondents) and for evening trips (57\%). At the other extreme, we observe that $41 \%$ of the sample rejected twice the trade-off between travel time and comfort ("No-No"). This category is over-represented in line $4(56 \%)$ and during morning peaks (54\%). Whilst this information is consistent with the variations of current in-vehicle comfort accross lines and periods, it may also be explained by the hypothetical extra travel time proposed to users: the first bid proposed to those who rejected the hypothetical scenario was twice the one faced by individuals accepting it (5.3 minutes and 10.9 minutes respectively).

Table 14: Descriptive statistics on hypothetical scenarios (2)

\begin{tabular}{|l|c|c|c|c|}
\hline & Yes-Yes & Yes-No & No-Yes & No-No \\
\hline Total (\%) & 25 & 17 & 17 & 41 \\
\hline Line 1 (\%) & 59 & 59 & 43 & 44 \\
Morning (\%) & 43 & 47 & 54 & 54 \\
\hline Expected density (pass $/ \mathbf{m}^{2}$ ) & 3.3 & 3.3 & 3.0 & 3.0 \\
Hypothetical density (pass $\left./ \mathbf{m}^{2}\right)$ & 1.2 & 1.3 & 1.1 & 1.3 \\
\hline Bid 1 (min) & 5.3 & 8.6 & 8.5 & 10.9 \\
Bid 2 (min) & 6.9 & 10.9 & 6.2 & 8.3 \\
\hline
\end{tabular}

Source: Field survey on platforms. 


\subsection{Full results tables}

Table 15: Determinants of comfort reference point: Ordered logit estimates

\begin{tabular}{|c|c|c|c|c|}
\hline & \multicolumn{4}{|c|}{ Dependant: comfort reference point } \\
\hline Count density & $\begin{array}{c}0.48^{* * *} \\
(0.08)\end{array}$ & $\begin{array}{c}0.47^{* * *} \\
(0.11)\end{array}$ & $\begin{array}{c}0.49^{* * *} \\
(0.11)\end{array}$ & $\begin{array}{c}0.48^{* * *} \\
(0.12)\end{array}$ \\
\hline Morning & $\begin{array}{c}-0.74^{* * *} \\
(0.10)\end{array}$ & $\begin{array}{c}-0.80^{* * *} \\
(0.14)\end{array}$ & $\begin{array}{c}-0.80^{* * *} \\
(0.15)\end{array}$ & $\begin{array}{c}-0.85^{* * *} \\
(0.15)\end{array}$ \\
\hline Line 1 & $\begin{array}{c}0.68^{* * *} \\
(0.16)\end{array}$ & $\begin{array}{c}0.68^{* * *} \\
(0.24)\end{array}$ & $\begin{array}{c}0.58^{* *} \\
(0.24)\end{array}$ & $\begin{array}{c}0.61^{* *} \\
(0.25)\end{array}$ \\
\hline In-vehicule travel time & & $\begin{array}{l}-0.00 \\
(0.01)\end{array}$ & & $\begin{array}{l}-0.00 \\
(0.01)\end{array}$ \\
\hline "Door-to-door" travel time & & $\begin{array}{l}0.00^{*} \\
(0.00)\end{array}$ & & $\begin{array}{l}0.00^{*} \\
(0.00)\end{array}$ \\
\hline Home-Work & & $\begin{array}{c}0.11 \\
(0.17)\end{array}$ & & $\begin{array}{c}0.02 \\
(0.17)\end{array}$ \\
\hline Line daily usage & & $\begin{array}{c}0.11 \\
(0.16)\end{array}$ & & $\begin{array}{c}0.15 \\
(0.16)\end{array}$ \\
\hline Age & & & $\begin{array}{l}-0.02 \\
(0.08)\end{array}$ & $\begin{array}{l}-0.02 \\
(0.08)\end{array}$ \\
\hline Male & & & $\begin{array}{c}0.05 \\
(0.14)\end{array}$ & $\begin{array}{c}0.05 \\
(0.14)\end{array}$ \\
\hline Parisian & & & $\begin{array}{l}-0.09 \\
(0.15)\end{array}$ & $\begin{array}{l}-0.01 \\
(0.16)\end{array}$ \\
\hline Income & & & $\begin{array}{l}0.10^{* *} \\
(0.04)\end{array}$ & $\begin{array}{l}0.10^{* *} \\
(0.04)\end{array}$ \\
\hline Car ownership & & & $\begin{array}{l}-0.14 \\
(0.16)\end{array}$ & $\begin{array}{l}-0.17 \\
(0.17)\end{array}$ \\
\hline Observations & 668 & 668 & 668 & 668 \\
\hline Pseudo $\mathbf{R}^{2}$ & 0.07 & 0.07 & 0.07 & 0.07 \\
\hline
\end{tabular}

Note: ${ }^{*}: p<0.10 ; * *: p<0.05 ; * * *: p<0.01$. 
Table 16: Influence of the time of day on the marginal disutility of travel time

\begin{tabular}{|c|c|}
\hline & Random effects probit \\
\hline \multirow{2}{*}{$\begin{array}{l}\text { Marginal disutility of travel time at: } \\
0 \text { pass } / \mathrm{m}^{2}\end{array}$} & \\
\hline & $\begin{array}{c}-0.149^{* * *} \\
(0.026)\end{array}$ \\
\hline \multirow[t]{2}{*}{1 pass $/ \mathrm{m}^{2}$} & $-0.160 * * *$ \\
\hline & $(0.028)$ \\
\hline \multirow[t]{2}{*}{$2 \operatorname{pass} / \mathrm{m}^{2}$} & $-0.170^{* * *}$ \\
\hline & $(0.027)$ \\
\hline \multirow[t]{2}{*}{$2.5 \mathrm{pass} / \mathrm{m}^{2}$} & $-0.189^{* * *}$ \\
\hline & $(0.030)$ \\
\hline \multirow[t]{2}{*}{3 pass $/ \mathrm{m}^{2}$} & $-0.207^{* * *}$ \\
\hline & $(0.033)$ \\
\hline \multirow[t]{2}{*}{$4 \mathrm{pass} / \mathrm{m}^{2}$} & $-0.210 * * *$ \\
\hline & $(0.034)$ \\
\hline \multirow{2}{*}{6 pass $/ \mathrm{m}^{2}$} & $-0.267 * * *$ \\
\hline & $(0.042)$ \\
\hline \multicolumn{2}{|l|}{ Interaction terms: } \\
\hline \multirow{2}{*}{ Morning commute $* 0$ pass $/ \mathrm{m}^{2}$} & $-0.102^{* * *}$ \\
\hline & $(0.032)$ \\
\hline \multirow[t]{2}{*}{ Morning commute $* 1$ pass $/ \mathrm{m}^{2}$} & $-0.085^{* * *}$ \\
\hline & $(0.033)$ \\
\hline \multirow[t]{2}{*}{ Morning commute $* 2$ pass $/ \mathrm{m}^{2}$} & $-0.088^{* * *}$ \\
\hline & $(0.032)$ \\
\hline \multirow[t]{2}{*}{ Morning commute $* 2.5$ pass $/ \mathrm{m}^{2}$} & $-0.102^{* * *}$ \\
\hline & $(0.036)$ \\
\hline \multirow[t]{2}{*}{ Morning commute $* 3$ pass $/ \mathrm{m}^{2}$} & $-0.097^{* *}$ \\
\hline & $(0.040)$ \\
\hline \multirow[t]{2}{*}{ Morning commute $* 4$ pass $/ \mathrm{m}^{2}$} & $-0.163^{* * *}$ \\
\hline & $(0.045)$ \\
\hline \multirow[t]{2}{*}{ Morning commute $* 6$ pass $/ \mathrm{m}^{2}$} & $-0.090^{*}$ \\
\hline & $(0.054)$ \\
\hline \multirow[t]{2}{*}{ Morning commute (dummy) } & 0.374 \\
\hline & $(0.272)$ \\
\hline \multirow[t]{2}{*}{ Constant } & $0.802^{* * *}$ \\
\hline & $(0.216)$ \\
\hline \multirow[t]{2}{*}{$\rho$} & $0.535^{*}$ \\
\hline & $(0.068)$ \\
\hline \multirow{2}{*}{$\begin{array}{l}\text { Log pseudo } \\
\text { Observations }\end{array}$} & -752.2 \\
\hline & e Haywood $668 \mathrm{Ma}$ \\
\hline
\end{tabular}

Note: ${ }^{*}: p<0.10 ; * *: p<0.05 ;{ }^{* * *}: p<0.01$ 


\subsection{Graphical representation of parameters}

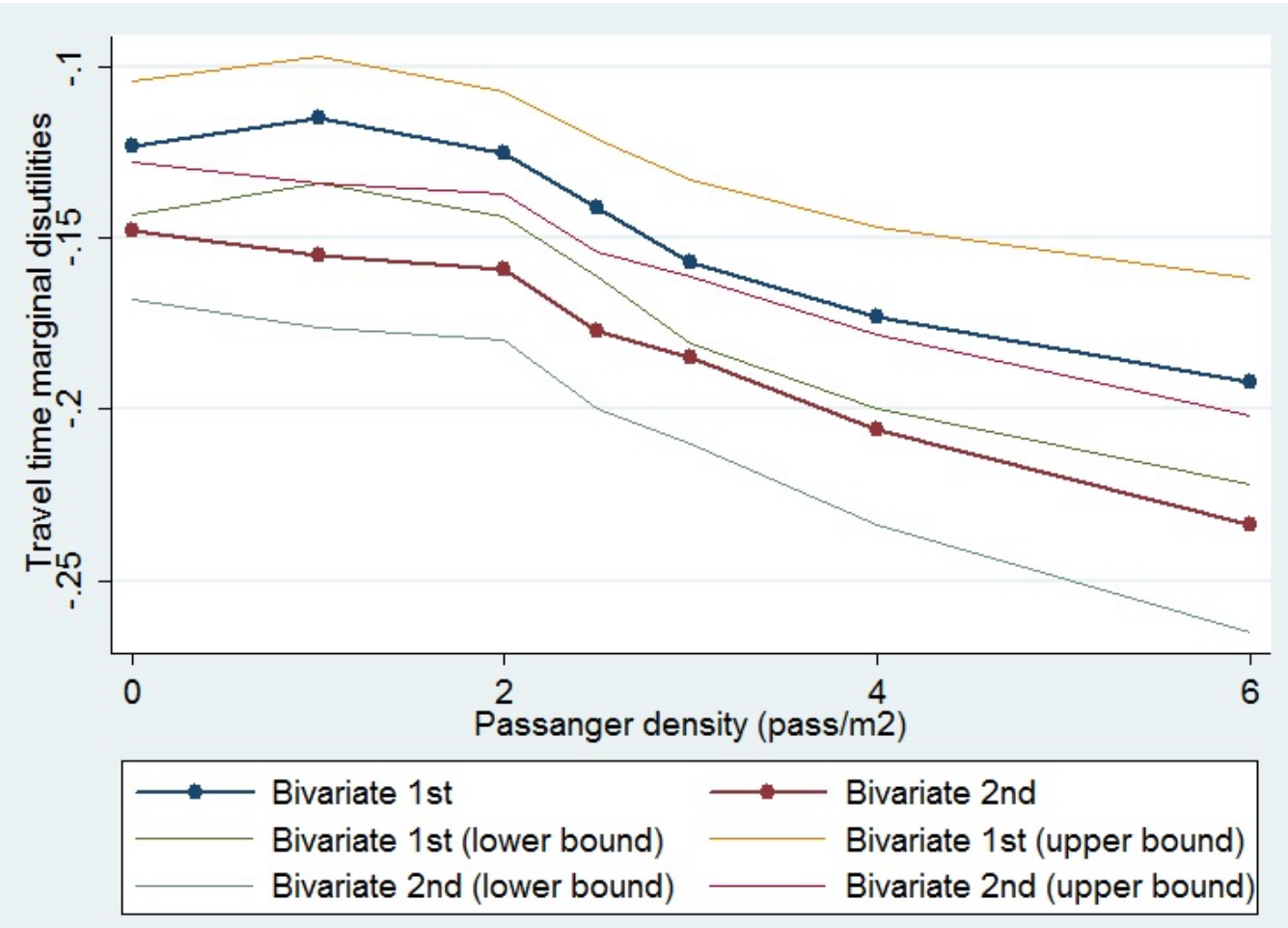

Figure 4: Confidence intervals (95\%) of time marginal disutilities estimated from first and second bids (with a bivariate probit) 


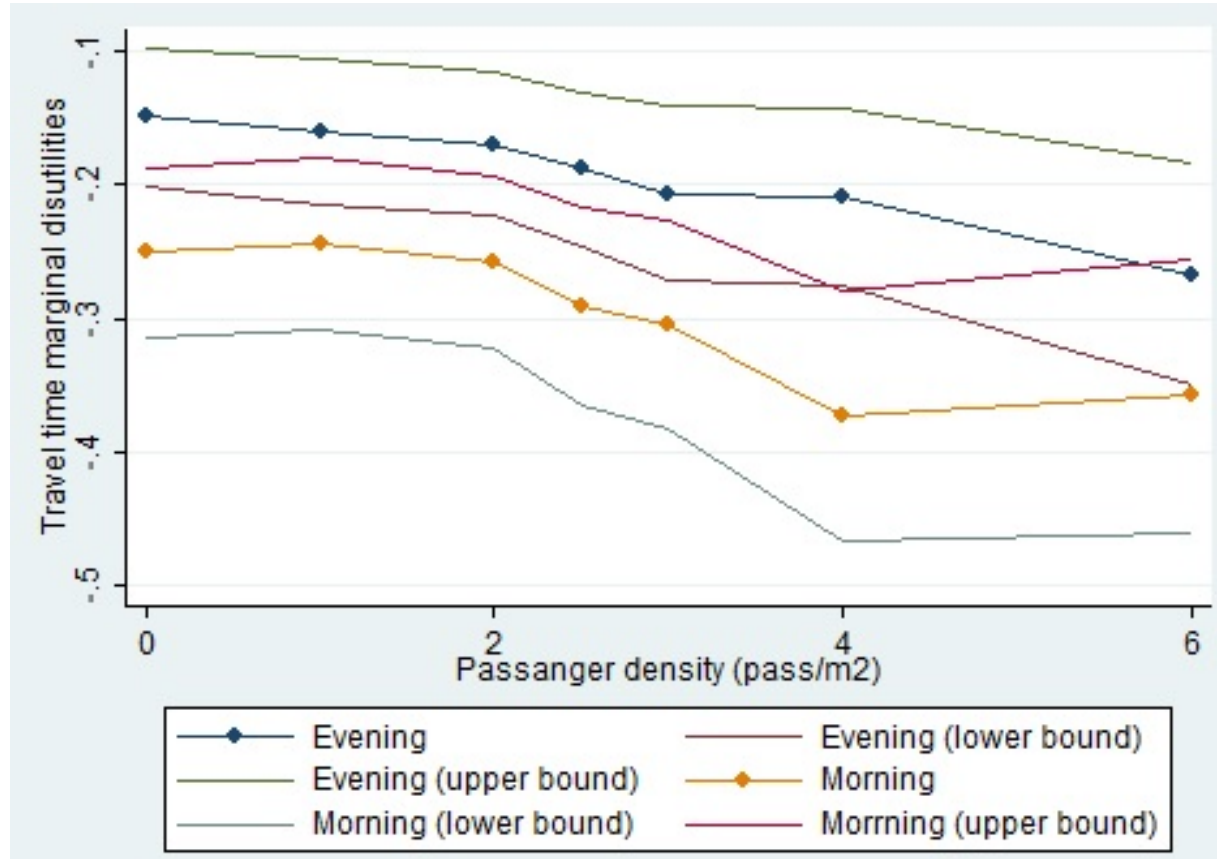

Figure 5: Marginal disutility of trip time (and 95\% confidence intervals) during morning and evening rush-hour transit (estimated with a random effects probit) 


\section{References}

Alberini, A., B. Kanninen, And T. Cameron (1997): "Modeling Response Incentive Effects in Dichotomous Choice Contingent Valuation," Land Economics, 73, 309-324.

Arnott, R., A. De Palma, and R. Lindsey (1990): "The Economics of Bottleneck," Journal of Urban Economcics, 27, 111-130.

Cameron, T. And J. Quiggin (1994): "Estimation Using Contingent Valuation Data from a "Dichotomous Choice with Follow-Up" Questionnaire," Journal of Environmental Economics and Management, 27, 218-234.

Cantwell, M., B. Caufield, and M. O'Mahony (2009): "Examining the Factors that Impact Public Transport Commuting Satisfaction," Journal of Public Transportation, 12, 1-22.

Commissariat GÉnéral du Plan (2001): Transports : choix des investissements et coût des nuisances, Commissariat Général du Plan, Goupe Présidé par M. Boiteux, L. Baumstarck rapporteur.

(2005): Révision du taux d'actualisation des investissements publics, Commissariat Général du Plan, Groupe Présidé par D. Lebègue.

Cox, T., J. Houdmont, And A. Griffiths (2006): "Rail passenger crowding, stress, health and safety in Britain," Transportation Research Part A: Policy and Practice, 40, 244-258.

CRCFRI (2012): "A literature review of passenger crowding on metropolitan railways: psychological, cultural human and economic factors," Project R2.104.

D4E (2005): "Guide des bonnes pratiques pour la mise en oeuvre de la méthode des couts de transport," Série Méthode.

de Palma, A., M. Kilani, And S. Proost (2011): "Discomfort in mass transit and its application for scheduling and pricing," Working Paper presented at the ITEA Conference.

Debrincat, L., J. Goldberg, H. Duchateau, E. Kroes, And M. Kouwenhowen (2006): "Valorisation de la régularité des radiales ferrées en Ile-de-France," Proceedings of the ATEC Congress, CD Rom edition. 
Dell'Olio, L., A. Ibeas, And P. Cecin (2011): "The Quality of Service desired by Public Transport Users," Transport Policy, 217-227.

Douglas, N. And G. Karpouzis (2006): "Estimating the passenger cost of train overcrowding," Paper presented at the 29th Australian Transport Research Forum.

Evans, G. And R. Wener (2007): "Crowding and personal space invasion on the train: Please don't make me sit in the middle," Journal of Environmental Psychology, 27, 90-94.

Feifei, Z. And J. Haicheng (2011): "A reinvestigation of crowding cost function form for public transit: linear or non-linear?" Paper presented at the ITEA Conference.

Flachaire, E. And G. Hollard (2007): "Starting-point bias and respondent uncertainty in dichotomous choice valuation surveys," Resource and Energy Economics, 29, 183-194.

HAAB, T. AND K. MCCONNEL (2003): Valuing Environmental and Natural Resources: the Econometrics of Non-Market Valuation, Edward Elgar.

Hanemann, W., J. Loomis, and B. Kanninen (1991): "Statistical Efficiency of Double-Bounded Dichotomous Choice Contingent Valuation," American Journal of Agricultural Economics, 1255-1263.

Haywood, L. And M. Koning (2012): "Avoir les coudes serrés dans le métro parisien : évaluation contingente du confort des déplacements," Revue d'Economie Industrielle, 111-144.

JarA-Diaz, S. And A. Gschwender (2003): "Towards a general microeconomic model for the operation of public transport," Transport Reviews, 4, 453-469.

Kopp, P. (2011): "The unpredicted rise of motorcycles: A cost benefit analysis," Transport Policy, 18, 613-622.

Kraus, M. (1991): "Discomfort Externalities and Marginal Cost Transit Fares," Journal of Urban Economics, 29, 249-259.

Kraus, M. And Y. Yoshida (2002): "The commuter's time-of-use decision and optimal pricing and service in urban mass transit," Journal of Urban Economics, 51, 170-195. 
Leurent, F., V. Breteau, And N. Wagner (2009): Cout marginal social de la congestion routiere. Actualisation et critique de l'approche Hautreux, LVMT, Rapport pour le compte du MEDDAT.

LI, Y. (2003): "Evaluating the Urban Commute Experience: A Time Perception Approach," Journal of Public Transportation, 6, 41-67.

Li, Z. And D. Hensher (2011): "Crowding and public transport: a review of willingness to pay evidence and its relevance in project appraisal," Transport Policy, 880-887.

LINDSEY, R. (2006): "Do economists reach a conclusion on road pricing?" Econ Journal Watch, 3, 292-379.

Litman, T. (2008): "Valuing Transit Service Quality Improvements," Journal of Public Transportation, 11, 43-64.

Malibach, M., C. Schreyer, H. Van Hessen, C. Doll, and B. PAWlowsKa (2008): Handbook on estimation of external costs in the transport sector, CE Delft, The Netherlands.

MinistèRE DE L'EQUIPEMENT (2005): Instruction-cadre relative aux méthodes d'évaluation économique des grands projets d'infrastructures de transport, Ministère de l'Equipement, des Transports, de l'Aménagement du Territoire, du Tourisme et de la Mer, version mise à jour le 27 mai 2005.

Mitchell, R. And R. Carson (1989): Using Surveys to Value Public Goods: The Contingent Valuation Method, Washington, D.C.: Resources for the Future/Johns Hopkins University Press.

Mohring, H. (1972): "Optimization and Scale Economies in Urban Bus Transportation," American Economic Review, 62, 591-604.

Newman, P. And J. Kenworthy (1989): Cities and Automobile Dependance. An International Sourcebook, Gower Technical, Sidney.

Observatoire de la mobilité de la ville de Paris (2000): "Bilan des Déplacements de la Ville de Paris," Disponible sur le site internet de la ville de Paris.

(2007): "Bilan des Déplacements de la Ville de Paris," Disponible sur le site internet de la ville de Paris.

(2009): "Bilan des Déplacements de la Ville de Paris," Disponible sur le site internet de la ville de Paris. 
ORSTIF (2010): "Enquête auprès des salariés d'Ile-de-France sur les transports en commun domicile-travail," Mimeo.

Parry, I., W. Harrington, And M. Walls (2007): "Automobile Externalities and Policies," Journal of Economic Literature, 65, 373-399.

Parry, I. And K. Small (2009): "Should Urban Transit Subsidies Be Reduced?" American Economic Review, 99, 700-724.

Proost, S. And K. Dender (2008): "Optimal urban transport pricing in the presence of congestion, economies of density and costly public funds," Transportation Research-Part A, 42, 1220-1230.

Prud'homme, R., M. Koning, L. Lenormand, and A. Fehr (2012): "Public Transport Congestion Costs: The Case of Paris Subway," Transport Policy, 21, 101-109.

Prud'homme, R. And P. Kopp (2008): "Worse than a Congestion Charge: Paris Traffic Restrain Policy," in Road Congestion Pricing Book, ed. by R. Richardson and C. Chang Hee, Edward Elgar, 252-272.

Régie Autonome des Transports Parisiens, . (2011): "Automatiser la ligne 1 : un défi technique, organisationnel et social," Rapport d'activité du groupe Ratp.

Small, K. And E. Verhoef (2007): The Economics of Urban Transportation - 2d Edition, Routledge.

Syndicat des Transports De la RéGion Ile-De-France (2009): Les transports en communs en chiffres 2000-2009, OMNIL.

Technologia (2010): "Etude d'impact des transports en commun de Région Parisienne sur la santé des salariés et des entreprises," Mimeo.

Tsekeris, T. And S. Voss (2009): "Design and Evaluation of Road Pricing: State-of-the-art and Methodological Advances," Netnomics, 5-52.

Wardman, M. (2001): "A Review of British Evidence on Time and Service Quality Valuations," Transportation Research E, 37, 107-128.

Wardman, M. And G. Whelan (2011): "Twenty years of rail crowding valuation studies: evidence and lessons from british experience," Transport Reviews, 31, 379-398. 
Wener, R., G. Evans, And P. Boately (2005): "Commuting stress: Psychological effects of a trip and spillover into the workplace," Transportation Research Board, 1924/2005, 112-117.

Whelan, G. And J. CRockett (2009): "An investigation of the willingness to pay to reduce rail overcrowding," Proceeding of the First International Conference on Choice Modelling, Harrogate, England. 